Research Article

\title{
Detailed Parametric Investigation and Optimization of a Composite Wing with High Aspect Ratio
}

\author{
Yu-shan Meng, Li Yan, Wei Huang $(D$, and Tian-tian Zhang \\ College of Aerospace Science and Engineering, National University of Defense Technology, Changsha, 410073 Hunan, China \\ Correspondence should be addressed to Wei Huang; gladrain2001@163.com
}

Received 10 March 2019; Revised 4 May 2019; Accepted 4 June 2019; Published 11 July 2019

Academic Editor: Antonio Viviani

Copyright (C) 2019 Yu-shan Meng et al. This is an open access article distributed under the Creative Commons Attribution License, which permits unrestricted use, distribution, and reproduction in any medium, provided the original work is properly cited.

\begin{abstract}
The large deformation problem of the wing with high aspect ratio cannot be avoided due to the large bending moment and poor torsional stiffness. The wing design follows the following procedure; firstly, the design indexes of high aspect ratio wing are preliminarily formulated referring to some parameters of the Predator UAV. Then, the aerodynamic analysis of the wing is performed, and the stress cloud diagram is obtained. Next, the finite element model of the wing is designed, and the static analysis is conducted in the ANSYS ACP module, and the unreasonable component size is changed. An appropriate thickness which is $12 \mathrm{~mm}$ is selected as the final thickness of the wing. Then, the analysis of laying methods of skin structure is conducted. Finally, the composite structure is proved to reduce the maximum deformation and maximum stress effectively compared with the metal wing.
\end{abstract}

\section{Introduction}

During the flight of an aircraft, the wing is crucial to the generation of the lift force [1]. The wing will be overdeformed or even destroyed once the stiffness of the wing is insufficient during the flight. The unstable elastic effect is very dangerous at the same time [2]; the shear force and bending moment caused by the aerodynamic force will increase from the tip to the root with the increase of the length of wings. As a result, the tip of the wing will have a larger warpage deformation, and the wing will be fatigued and broken easier.

As for the wing, the strength of the wing cannot be increased without limit. Excessive strength will also lead to excessive conservative margin, which will not only increase the weight of the structure but also decrease the performance of the aircraft. Therefore, a large number of composite materials are used in the high aspect ratio wing in this paper. The wing of UAV is a typical wing with large aspect ratio. Due to its long wingspan, the structural design problems of the wing are more significant. The application of lightweight and highstrength composite materials can not only reduce the weight of the structure but also make use of the elasticity of composite materials to realize the complex bending and torsion deformation of the wing, so as to meet the requirements of composite stiffness and strength of the structure [3].

Scholars at home and abroad have been paying attention to its parametric design, new configuration, and optimization [1]. Shi et al. [4] used numerical simulation analysis method to study the geometric nonlinear deformation of UAV with large aspect ratio and solved the problem of model establishment and structural response of flexible wing. Based on CFD/CSD coupling method and Kriging approximation technology, Lu et al. [5] established a static aerostatic optimization interpolation model for the wing and applied the hybrid optimization algorithm to the aerostatic optimization design of the wing. Shokrieh and Behrooz [6] used finite element analysis software to calculate the torsional stiffness of the composite wing and the mass distribution along the wing, calculated the natural frequencies of the bending and torsional vibrations of the wing and the rotational natural frequency of the aileron, and finally drew the conclusion that there was no flutter within the design speed range of the wing. Takeda et al. [7] used FBG sensors to test the durability of composite wing structures, including service life and cyclic fatigue test. The results demonstrate that FBG sensors can be used to monitor the structural safety of large composite wing 
TABle 1: Design parameters of the wing employed in the current study.

\begin{tabular}{lccccc}
\hline Wingspan $(\mathrm{m})$ & Root chord $(\mathrm{m})$ & Tip chord $(\mathrm{m})$ & Cruising Mach number & Aspect ratio & Flight height $(\mathrm{m})$ \\
\hline 14.8 & 1.1 & 0.4 & 0.6 & 19.73 & 7620 \\
\hline
\end{tabular}

structures. Lu et al. [5] carried out the finite element analysis of a composite wing, and this proves that the finite element approach is effective in the analysis and investigation of the wing structure. The performance of the composite structure is superior to that of the metal structure and alloy steel structure in weight reduction and other performances. Taig [8] stated that the most basic choice in the wing design is material selection and structural form selection, and he introduced the principles used to achieve design objectives, design requirements, and design constraints in detail. Kim et al. [9] used the multilevel optimization method to develop the optimization framework of the composite wing structure, and certain constraints were set to enhance the aeroelastic stability of the aircraft by seeking the best structural characteristics such as mass and torsional stiffness. Patil et al. [10] analyzed the aeroelastic instability problem of the aircraft reliably and modeled the important structural features of the wing. Finally, they concluded the effects of structural characteristics and aerodynamics on the structural flutter velocity and oscillation amplitude.

Njuguna [11] carried out the flutter study of composite structure and briefly introduced the influence of fiber layup direction on flutter. Omprakash et al. [12] carried out the multivariable optimization design of the wing, and the thickness and angle of the layer were both analyzed. The obtained results show that the structural stability, continuity, and weight reduction performance of the optimal design of the wing by means of the genetic algorithm are better than those using traditional methods. In the aspect of laying design, Feng et al. [13] used the ANSYS finite element analysis software to optimize the layer of the wing under the premise that the parameters of the configuration are known, and finally, they got the optimal layering scheme. Liu et al. [14] used the finite element simulation approach to formulate the laying schemes for several different wing layout forms, validate the wing deployment test, and establish a set of research schemes which can effectively improve the ratio of wing load to structure weight.

\section{Aerodynamic Analysis and Structural Design of the Wing}

The design parameters of the wing are preliminarily formulated referring to some dimensions and flight parameters of the Predator UAV, as shown in Table 1.

\subsection{Aerodynamic Analysis of NACA 2412. NACA 2412 airfoil} is chosen as the design airfoil in this paper. The geometric model of NACA 2412 drawn in CATIA is imported into ICEM CFD [15]. The generated meshes that meet the quality requirements are shown in Figure 1. Then the aerodynamic analysis of NACA 2412 is simulated in FLUENT. The pressure cloud diagram of the airfoil surface is obtained as shown in Figure 2.

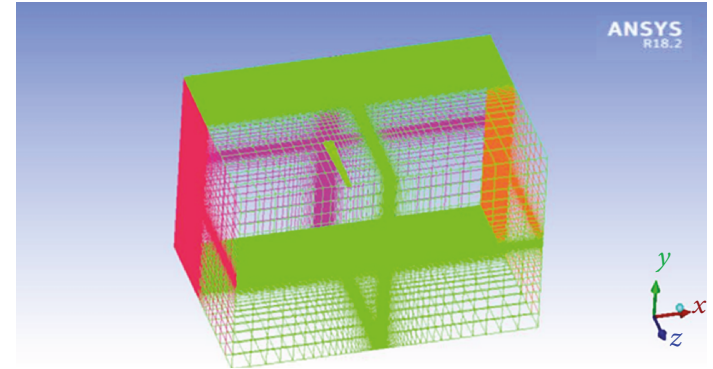

Figure 1: Structural mesh of NACA 2412.

For the postprocessing of the calculation of the external flow field of the wing in the current study, the most notable thing is the lift and drag characteristics of the wing. It can be seen from Figure 2 that an obvious wingspan flow occurs around the wingtip because of the long wingspan of the wing, which is a three-dimensional turbulent flow. This is because there is no separation effect at the end of the wing, and the high-pressure airflow on the low surface of the wing will go around the wingtip and roll up to the upper surface. The longer the wingspan is, the more obvious the wingtip flow around the wingtip will become.

2.2. Structural Design of the Wing. A widely accepted design scheme of composite structures in the field of aeronautics is the "Building Block" [16]; in this paper, the wing designed in this paper is simplified into a structure with only beams, ribs, and skins. It adopts a double-beam structure with good bending and torsion rigidity to obtain a structural layout with high bearing efficiency [17]. The size of the beam will not be particularly large since the skin of the wing can provide part of the flexural stiffness, and the desired results can be obtained by increasing the thickness of the skin. The spar is essentially a shear beam as the main bearing member, and the I-beam is used and arranged according to the equal percentage line. The initial size of the fore beam and the rear beam is shown in Figures 3(a) and 3(b).

The ribs are simplified to a structure with only webs so as to facilitate the analysis of the model in this paper. In this paper. 14 wing ribs are designed for the wing, of which the root is a reinforced wing rib with the thickness of $9 \mathrm{~mm}$ and the others are ordinary wing ribs with a thickness of $6 \mathrm{~mm}$. In addition, weight-reducing holes are arranged on the wing ribs to reduce the weight of the structure. It is known from engineering experience that the most suitable distance between the two nearest ribs is $500 \mathrm{~mm}$ to $600 \mathrm{~mm}$ [18], and the distance is chosen as $560 \mathrm{~mm}$.

\section{Preliminary Static Analysis of the Composite Wing}

The ANSYS Composite Pre/Post (ANSYS ACP) composite material special module is the pre- and postprocessing 


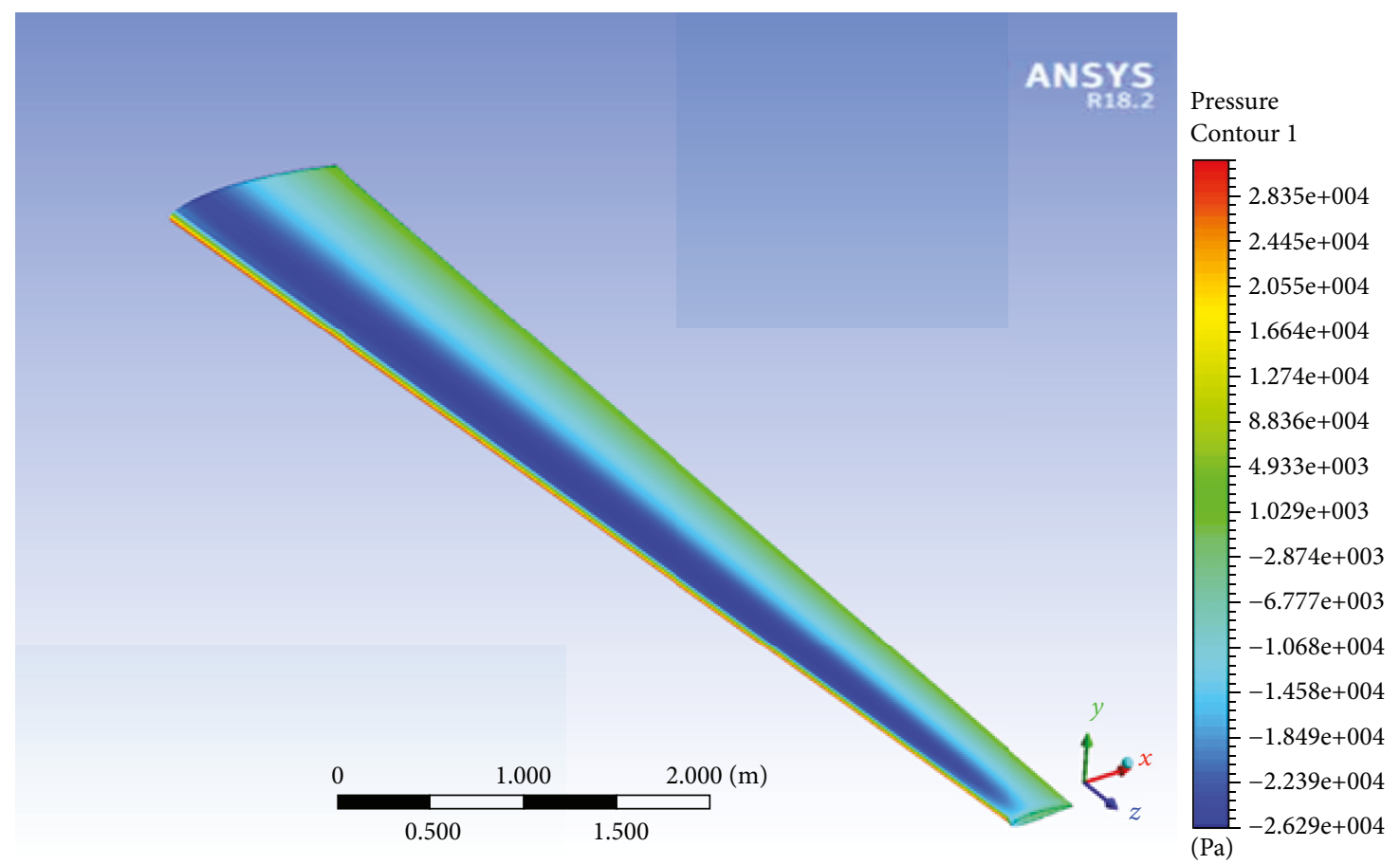

Figure 2: Pressure contour on the NACA 2412 airfoil.

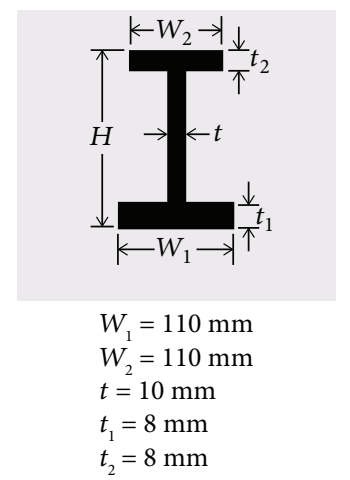

(a)

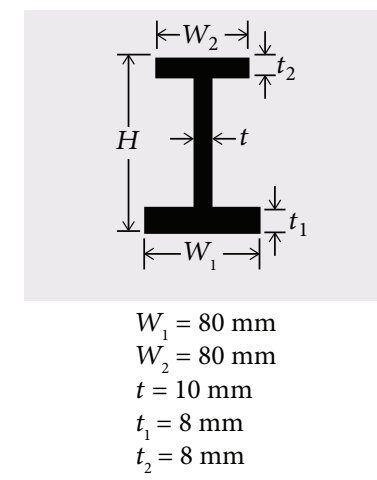

(b)

Figure 3: The size of fore beam and the rear beam.

module of the composite material analysis scheme [18]. All composite material definitions are created and mapped to the finite element grid in the preprocessing module. In the postprocessing module, the resolving result file is imported into the process to evaluate and visualize the composite structure. The finite element analysis of the wing is carried out in the Workbench collaborative simulation environment developed by ANSYS.

For the composite wing in this paper, the skin and wing ribs are made of composite materials, while the aluminum alloy material is used for beam structure to overcome the shortcomings of poor shear resistance of the composite material. The material parameters are shown in Table 2 and Table 3.

In this paper, the $X-Y$ direction of the reference coordinate system coincides with the main direction of the material.
In Table 2 and Table 3, part of the performance properties of materials is defined as follows:

(i) $\sigma_{b}$-tensile ultimate strength, it refers to the maximum stress that the material can bear before breaking

(ii) $S$-shear $X Y$

(iii) $X$-tensile $X$ direction

(iv) $Y$-tensile $Y$ direction

(v) $\mu_{12}$-Poisson's ratio $X Y Y$ direction

(vi) $X^{\prime}$-compressive $X$ direction

(vii) $Y^{\prime}$-compressive $Y$ direction 
TABle 2: Properties of LY12 aluminum alloy.

\begin{tabular}{lccc}
\hline$\rho\left(\mathrm{kg} / \mathrm{m}^{3}\right)$ & $E(\mathrm{GPa})$ & $\mu$ & $\sigma_{b}(\mathrm{MPa})$ \\
\hline 2780 & 70610 & 0.3 & 432 \\
\hline
\end{tabular}

Table 3: Properties of epoxy matrix composite.

\begin{tabular}{lcccc}
\hline$\rho\left(\mathrm{kg} / \mathrm{m}^{3}\right)$ & $E_{1}(\mathrm{GPa})$ & $E_{2}(\mathrm{GPa})$ & $\mu_{12}$ & $G_{12}(\mathrm{GPa})$ \\
1600 & 181 & 10.3 & 0.28 & 7.17 \\
\hline$X(\mathrm{MPa})$ & $X^{\prime}(\mathrm{MPa})$ & $Y(\mathrm{MPa})$ & $Y^{\prime}(\mathrm{MPa})$ & $S(\mathrm{MPa})$ \\
1500 & 700 & 40 & 246 & 68 \\
\hline
\end{tabular}

When laminating the composite structures, the $0^{\circ}$ fiber direction (or reference direction) of the material is defined by the tool coordinate system Rosettes in the ANSYS ACP module, and the $X$ axis of the tool coordinate system is the $0^{\circ}$ direction of the fiber. According to the empirical formula, as for the skin, when the ratio of three ply angles $( \pm 45,0$, and $90)$ is $60: 30: 10$, the structure performance of the wing is the best. In the initial finite element static analysis, as for the skin, the stacking sequence is $[45 / 90 / 0 / 90 /-45]_{s}$, and subscript "s" denotes symmetrical layers. For the wing ribs, which are mainly subjected to shear stress [8], the stacking sequence is $[ \pm 45]_{5 s}$. The thickness and layer parameters of the ribs are formulated as Table 4.

The finite static element analysis is carried out following the flow in Figure 4; by checking the mesh quality, it is found that the Element Quality of the finite mesh is mostly greater than 0.5 , and the Skewness is mostly less than 0.6; meanwhile, the Jacobian Ratio is less than 10, so it can be considered that the grid is efficient.

According to the actual situation, a fixed support is imposed on the wing root as the boundary condition of the wing, as shown in Figure 5.

\section{Analysis and Selection of Skin Thickness}

After determining the laying methods of skin and wing ribs, the discussion of the skins with different thicknesses is carried out in the ACP. The internal finite element mesh of the wing in Workbench is shown in Figure 6; according to the statistics of mesh, the number of nodes is 35924 , and the number of elements is 24142 . In this paper, the pressure on each layer of the wing is different. When performing the analysis, the stress value of fibers in each layer needs to be taken into consideration after lamination. Since composite materials are anisotropic materials and the first failure point may be in the inner layer, so it should be guaranteed that the layer with the largest stress value is not invalid.

According to the existing simulation research [19], six different thickness skins are selected for analysis in order to select the optimum thickness of the skin. The obtained results are organized into Table 5 .

In this paper, the Inverse Reserve Factor is the inverse of the Reverse Factor, and the failure load is equal to the load applied on the structure divided by IRF; when IRF is larger than 1 , it is concluded that the structure is broken [20].
TABLE 4: The thickness and layer parameters of the ribs.

\begin{tabular}{lcccc}
\hline & $\begin{array}{c}\text { Total } \\
\text { thickness } \\
(\mathrm{mm})\end{array}$ & $\begin{array}{c}\text { Layer } \\
\text { groups }\end{array}$ & $\begin{array}{c}\text { Layers of } \\
\text { each } \\
\text { group }\end{array}$ & $\begin{array}{c}\text { Thickness of } \\
\text { each layer } \\
(\mathrm{mm})\end{array}$ \\
\hline Reinforced wing rib & 9 & 6 & 10 & 0.15 \\
Normal wing rib & 6 & 4 & 10 & 0.15 \\
\hline
\end{tabular}

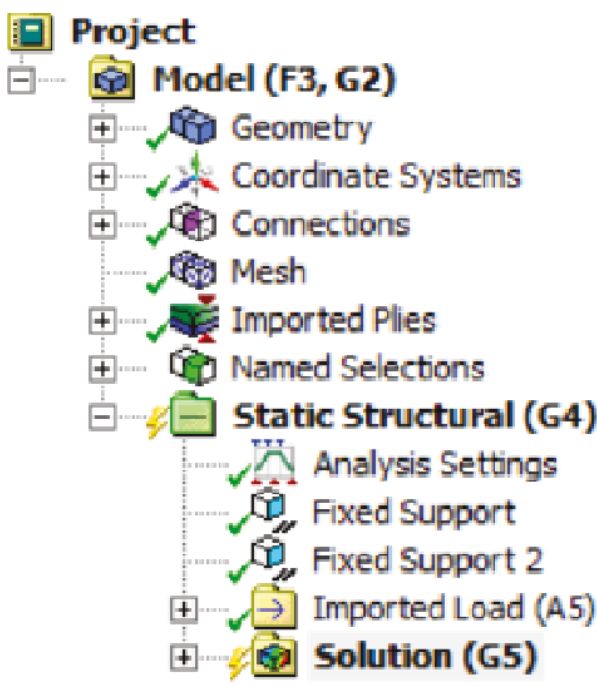

Figure 4: The workflow of the static analysis.

It can be seen that when the thickness of the skin is $4 \mathrm{~mm}$, $6 \mathrm{~mm}$, and $8 \mathrm{~mm}$, respectively, the Inverse Reserve Factor of the wing becomes larger and larger from the wingtip to the wing root. At the junction of the wing root and the flange of the front beam, the stress and the failure coefficients are the greatest, and the maximum deformation occurs at wingtip, which are in line with the actual situation. The reason is that the aerodynamic force of the wing near the leading edge is the largest, and the front beam of the wing bears the most of bending moments. Only by increasing the thickness of the skin, the improvement of the strength of the wing will not be more obvious.

One possible way of handling this problem is to change the size of beams and ribs, so the size of the front beam should be increased from $10 \mathrm{~mm}$ to $12 \mathrm{~mm}$, and the thickness of the upper and lower flanges should be further increased from $8 \mathrm{~mm}$ to $10 \mathrm{~mm}$. After changing the size of the beam, the thickness of the skin should be increased until the thickness of the front beam that meets the strength requirements is found. When the thickness of the skin is $10 \mathrm{~mm}$, it can be seen that after changing the size of the beam, the maximum deformation of the wing is reduced, and the strength is greatly improved. However, the Inverse Reserve Factor of the upper airfoil is still greater than 1. Therefore, the thickness of the skin should be further increased to $12 \mathrm{~mm}$ and $14 \mathrm{~mm}$, respectively.

It can be seen intuitively from Table 5 that when the thickness of the skin is $12 \mathrm{~mm}$, the strength of the wing structure is consistent with the design requirements. The Inverse 


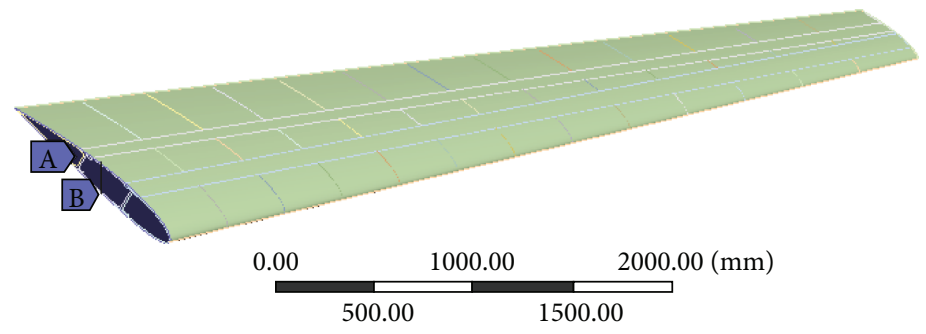

B: Static structural

Fixed support

Time: $1 . s$

A Fixed support

B Fixed support 2

FIGURE 5: The boundary condition of the wing.

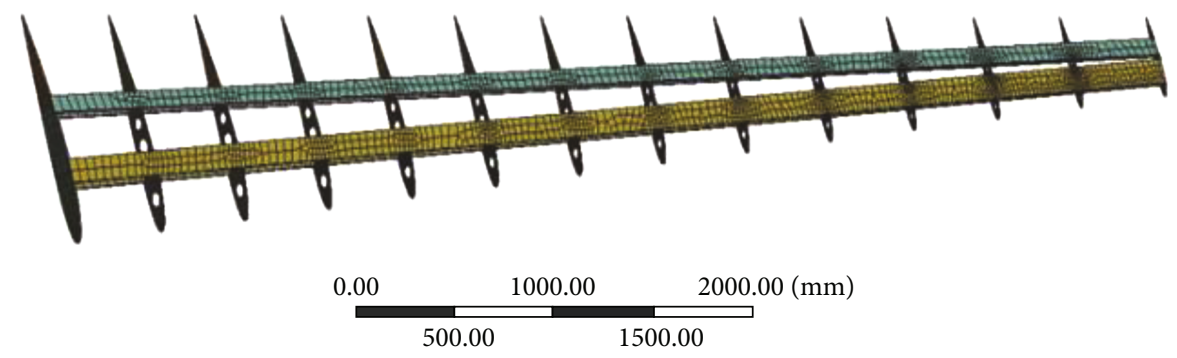

Figure 6: Internal finite element mesh.

TABLE 5: Mechanical properties of the skins with different thicknesses.

\begin{tabular}{lccccc}
\hline $\begin{array}{l}\text { Thickness } \\
(\mathrm{mm})\end{array}$ & $\begin{array}{c}\text { Maximum } \\
\text { deformation }(\mathrm{mm})\end{array}$ & $\begin{array}{c}\text { Maximum stress of the } \\
\text { upper wing }(\mathrm{MPa})\end{array}$ & $\begin{array}{c}\text { Maximum stress of the } \\
\text { lower wing }(\mathrm{MPa})\end{array}$ & $\begin{array}{c}\text { Maximum Inverse Reserve } \\
\text { Factor of the upper wing }\end{array}$ & $\begin{array}{c}\text { Maximum Inverse Reserve } \\
\text { Factor of the lower wing }\end{array}$ \\
\hline 4 & 1031.5 & 713.55 & 734.76 & 3.9932 & 4.0353 \\
6 & 873.67 & 605.94 & 604.69 & 2.6546 & 3.154 \\
8 & 698.17 & 516.69 & 513.87 & 2.313 & 1.943 \\
10 & 599.12 & 453.43 & 471.95 & 0.89972 & 0.95074 \\
12 & 420.56 & 365.37 & 363.24 & 0.60421 & 0.61564 \\
14 & 322.25 & 320.02 & 321.23 & 0.54848 & 0.49358 \\
\hline
\end{tabular}

Reserve Factor of the upper and lower airfoil layers is much smaller than 1. And the thickness of the skin has little impact on the deformation and stiffness of the wing even though it is further increased, and it will increase the weight of the structure instead. Therefore, considering the structural stiffness performance and weight reduction requirements, the thickness of the wing skin designed in this paper is $12 \mathrm{~mm}$.

When the thickness of the skin is $12 \mathrm{~mm}$, the deformation and stress cloud diagrams are obtained as Figures 7-9.

According to the above-mentioned proposed size parameters, the internal skeleton model of the wing is shown in Figure 10.

\section{Change the Laying Methods}

5.1. Change the Layer Sequence. The laying methods have great influence on the properties of the structure. In this section, keep the angle of the skin layer unchanged, change the laying sequence, and make the $\pm 45^{\circ}, 90^{\circ}$, and $0^{\circ}$ layers as the outermost layer, respectively. The finite element static analysis is performed to compare and analyze the maximum deformation of the wingtip and the maximum stress and failure performance of the layer under different conditions. Each layup sequence has 10 layup groups; each group has 10 single layers and the thickness of each layer is $0.12 \mathrm{~mm}$. The static analysis of six different layup sequences is performed as below.

When the layer sequence is $[45 / 0 / 90 / 0 /-45]_{s}$, the deformation and stress cloud diagrams are obtained as Figures 11-13.

It can be obtained that when the layer sequence is $[45 / 0 / 90 / 0 /-45]_{s}$, the maximum deformation of the wing is $427.95 \mathrm{~mm}$, the maximum stress of the upper wing is $366.63 \mathrm{MPa}$, and the maximum stress of the lower wing is $367.58 \mathrm{MPa}$. 
ACP Model

2018/5/19 08:32

ANSYS

Deformation-usum

Element-Wise

Unit: $\mathrm{mm}$

Set: 1-Time/Freq: 1.0 (Last)

Max: 420.56

Min: 0

Deformation.1

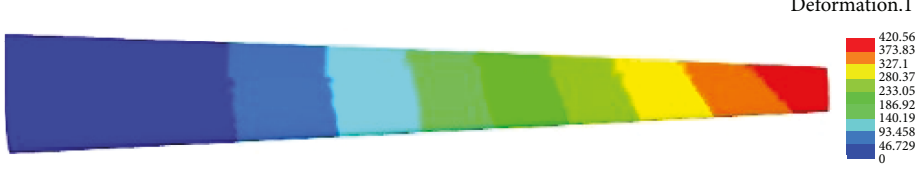

FIGURE 7: Deformation cloud diagram with the thickness of the skin being $12 \mathrm{~mm}$.

$\begin{array}{lr}\text { ACP Model } & \text { ANSYS } \\ \text { 2018/5/31 08:58 } & \\ \text { Stress -s1-bot } & \\ \text { Ply-Wise } & \\ \text { Unit: MPa } & \\ \text { Set 1-Time/Freq: } 1.0 \text { (Last) } & \\ \text { Max: } 365.37 & \\ \text { Min: -329.85 } & \\ \text { Selection: } & \text { Stress.1 } \\ \text { AP-P1L4_ModelingPly: } 4 & 365.37 \\ & 28.13 \\ & 213.88 \\ & 133.63 \\ & 56.38 \\ & -20.865 \\ -9.112 \\ & -15.36 \\ & -252.61 \\ & -329.85\end{array}$

Figure 8: Stress cloud diagram of the upper wing with the thickness of the skin being $12 \mathrm{~mm}$.

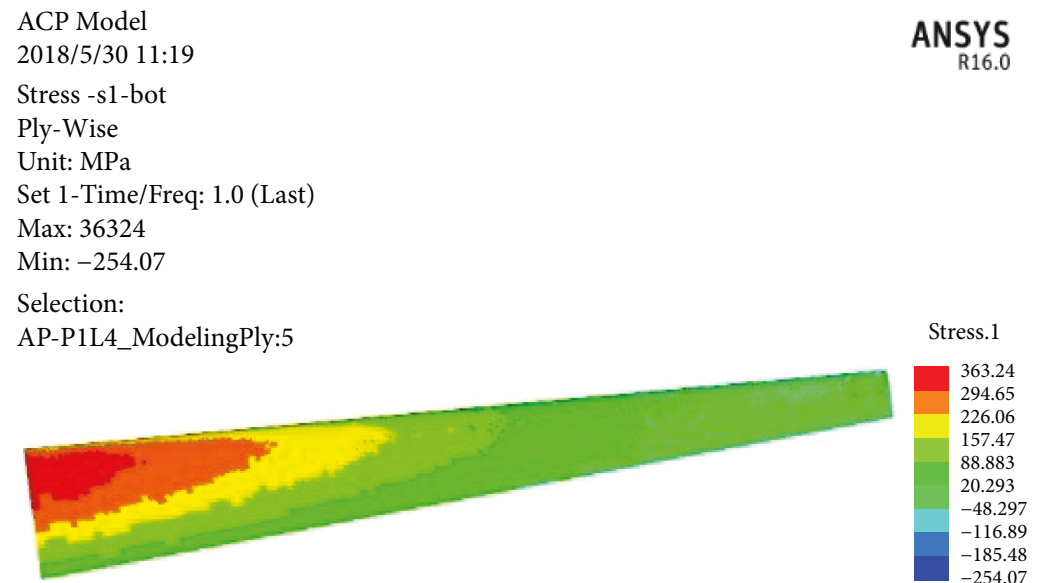

FIGURE 9: Stress cloud diagram of the lower wing with the thickness of the skin being $12 \mathrm{~mm}$.

When the layer sequence is $[0 / 45 / 90 /-45 / 0]_{s}$, the deformation and stress cloud diagrams are obtained as Figures 14-16.

It can be obtained that when the layer sequence is $[0 / 45 / 90 /-45 / 0]_{s}$, the maximum deformation of the wing is $461.22 \mathrm{~mm}$, the maximum stress of the upper wing is $401.83 \mathrm{MPa}$, and the maximum stress of the lower wing is 400.36 MPa.
When the layer sequence is $[0 / 90 / 45 / 90 / 0]_{s}$, the deformation and stress cloud diagrams are obtained as Figures 17-19.

It can be obtained that when the layer sequence is $[90 / 45 / 0 /-45 / 90]_{s}$, the maximum deformation of the wing is $475.49 \mathrm{~mm}$, the maximum stress of the upper wing is $405.12 \mathrm{MPa}$, and the maximum stress of the lower wing is 409.02 MPa. 


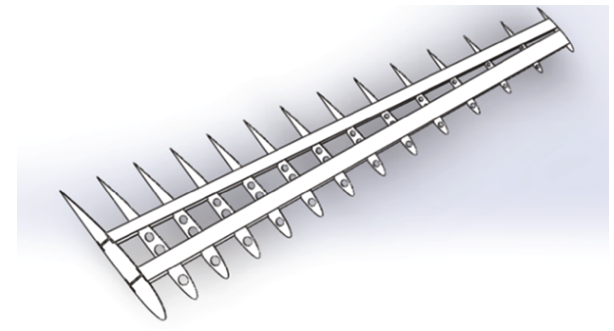

FIGURE 10: Model of the overall internal skeleton with the thickness of the skin being $12 \mathrm{~mm}$.

When the layer sequence is $[90 / 45 / 0 /-45 / 90]_{s}$, the deformation and stress cloud diagrams are obtained as Figures 20-22.

It can be obtained that when the layer sequence is $[90 / 45 / 0 /-45 / 90]_{S}$, the maximum deformation of the wing is $446.93 \mathrm{~mm}$, the maximum stress of the upper wing is $385.41 \mathrm{MPa}$, and the maximum stress of the lower wing is 388.24 MPa.

When the layer sequence is $[90 / 0 / 45 / 0 / 90]_{\mathrm{s}}$, the deformation and stress cloud diagrams are obtained as Figures 23-25.

It can be obtained that when the layer sequence is $[90 / 0 / 45 / 0 / 90]_{s}$, the maximum deformation of the wing is $451.71 \mathrm{~mm}$, the maximum stress of the upper wing is 393.48 $\mathrm{MPa}$, and the maximum stress of the lower wing is $398 \mathrm{MPa}$. The obtained results are organized into Table 6.

By comparing the results in Table 6, the following conclusions can be drawn:

(1) The structural stiffness of the wing can be improved by changing the laying sequence of the skin, and the influence of the laying sequence on the deformation of the wing is within several centimeters

(2) The deformation of the wingtip is the smallest, and the stress is the smallest when the \pm 45 ply is located at the outermost part of the ply. The deformation of the wingtip is the largest when the 0 ply is located at the outermost part of the ply, and the failure coefficient is also the largest. When the outermost layer is 90 degrees, the performance is in the middle

(3) In order to improve the stiffness of the structure and reduce the deformation and the failure coefficient, the \pm 45 and 90 layers should be laid on the outermost layer, and the 0 layers should be laid on the interior of the layers as far as possible

5.2. Change the Layer Angle. Keep the layer sequence unchanged, change the layer angle, and analyze the structural properties of the ply with different angles.

When the layer angle is \pm 45 alone, the deformation and stress cloud diagrams are obtained as Figures 26-28.

It can be obtained that the maximum deformation of the wing is $564.55 \mathrm{~mm}$, the maximum stress of the upper wing is $440.19 \mathrm{MPa}$, and the maximum stress of the lower wing is 447.24 MPa.

When the layer angle is 45 and 0 , the deformation and stress cloud diagrams are obtained as Figures 29-31.
It can be obtained that the maximum deformation of the wing is $493.56 \mathrm{~mm}$, the maximum stress of the upper wing is $449.53 \mathrm{MPa}$, and the maximum stress of the lower wing is $434.73 \mathrm{MPa}$.

When the layer angle is 90 and 0, the deformation and stress cloud diagrams are obtained as Figures 32-34.

It can be obtained that the maximum deformation of the wing is $456.47 \mathrm{~mm}$, the maximum stress of the upper wing is $420.91 \mathrm{MPa}$, and the maximum stress of the lower wing is $420.5 \mathrm{MPa}$.

When the layer angle is 45 and 90, the deformation and stress cloud diagrams are obtained as Figures 35-37.

It can be obtained that the maximum deformation of the wing is $485 \mathrm{~mm}$, the maximum stress of the upper wing is 434.27 $\mathrm{MPa}$, and the maximum stress of the lower wing is $432.86 \mathrm{MPa}$.

When the layer angle is \pm 45 and 90 , the deformation and stress cloud diagrams are obtained as Figures 38-40.

It can be obtained that the maximum deformation of the wing is $470.46 \mathrm{~mm}$, the maximum stress of the upper wing is $420.91 \mathrm{MPa}$, and the maximum stress of the lower wing is 416.36 MPa.

The obtained results are organized into Table 7 .

By comparing the results in Table 7 , the following conclusions can be drawn:

(1) Comparing the results of the first three groups with the last group, the second group with the fifth group, it can be seen that the structural deformation and failure coefficients with two angles are smaller than those with a single angle and larger than those with four angles at the same time. It means that the strength of the layer with standard angle mixed is higher than that with a single layer. When laminating composite structures, we should adopt the mixed layers as far as possible

(2) By comparing the results of the second group with the third group, it can be seen that the bending strength of 0 and 90 orthogonal ply is greater than that of 0 and 45 oblique ply

(3) By comparing the results of the third group with the fourth group, it can be concluded that the bending deformation of the structure with 45 only is greater than the structure with \pm 45 . It shows that the principle of equilibrium symmetry should be adopted in the process of laying and the \pm 45 layer should be adopted at the same time

5.3. Change the Layer Ratio. Keep the angle and the layup sequence unchanged; adjust the proportion of the four angles $( \pm 45,90$, and 0$)$ in the laminate layer. The following is an analysis comparison of the eight different angle proportions.

When the layer ratio is $10 \% / 10 \% / 80 \%$, the deformation and stress cloud diagrams are obtained as Figures 41-43.

It can be obtained that the maximum deformation of the wing is $523.99 \mathrm{~mm}$, the maximum stress of the upper wing is 434.1 $\mathrm{MPa}$, and the maximum stress of the lower wing is 423.11 MPa. 
ACP Model

2018/5/27 19:30

ANSYS

Deformation-usum

Element-Wise

Unit: $\mathrm{mm}$

Set: 1-Time/Freq: 1.0 (Last)

Max: 427.94

Min: 0

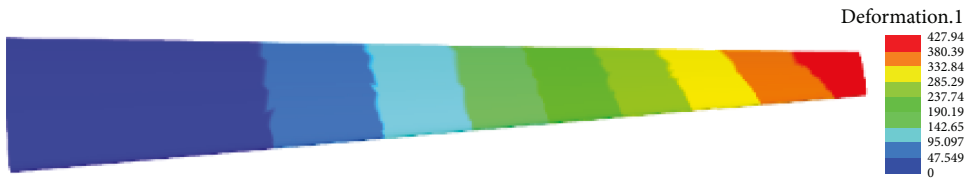

Figure 11: Deformation cloud diagram with the layer sequence being $[45 / 0 / 90 / 0 /-45]_{s}$.

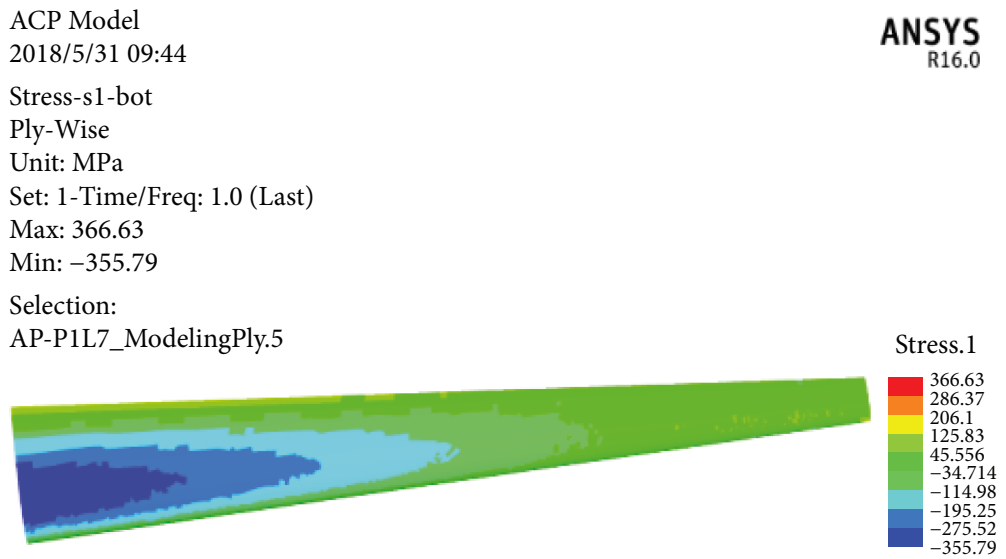

FIgURE 12: Stress cloud diagram of the upper wing with the layer sequence being $[45 / 0 / 90 / 0 /-45]_{S}$.

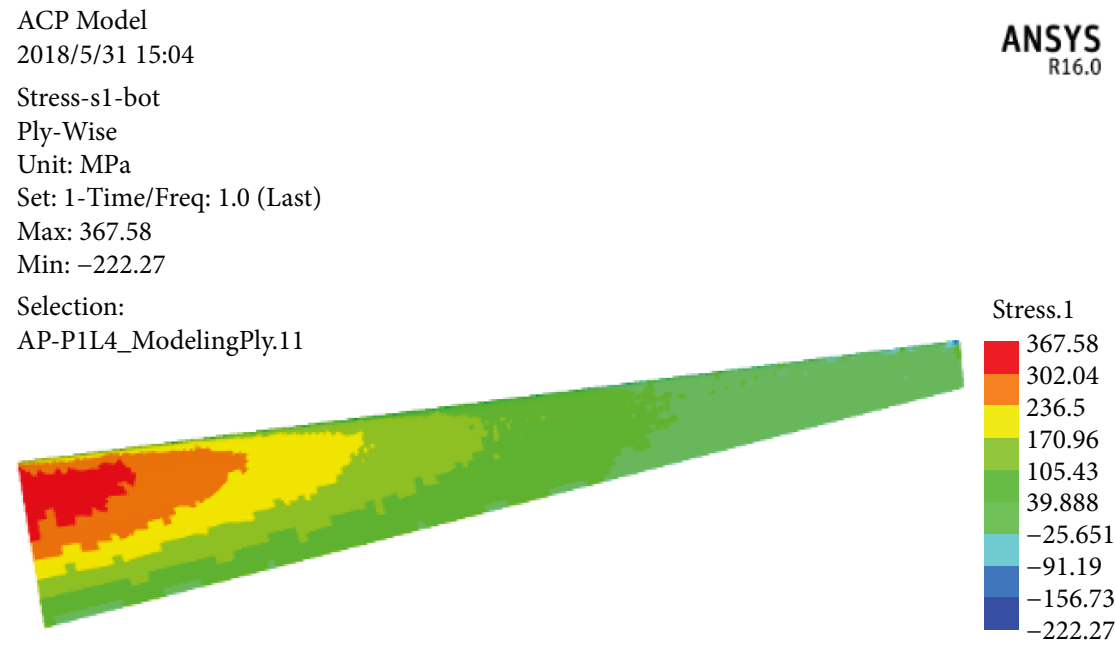

FIGURE 13: Stress cloud diagram of the lower wing with the layer sequence being $[45 / 0 / 90 / 0 /-45]_{s}$.

When the layer ratio is $20 \% / 20 \% / 60 \%$, the deformation and stress cloud diagrams are obtained as Figures 44-46.

It can be obtained that the maximum deformation of the wing is $498.69 \mathrm{~mm}$, the maximum stress of the upper wing is $414.68 \mathrm{MPa}$, and the maximum stress of the lower wing is 418.84 MPa.
When the layer ratio is $30 \% / 60 \% / 10 \%$, the deformation and stress cloud diagrams are obtained as Figures 47-49.

It can be obtained that the maximum deformation of the wing is $456.47 \mathrm{~mm}$, the maximum stress of the upper wing is $405.12 \mathrm{MPa}$, and the maximum stress of the lower wing is 409.44 MPa. 
ACP Model

2018/5/31 22:10

ANSYS

Deformation-usum

Element-Wise

Unit: $\mathrm{mm}$

Set: 1-Time/Freq: 1.0 (Last)

Max: 40.1.22

Min: 0

Deformation.1

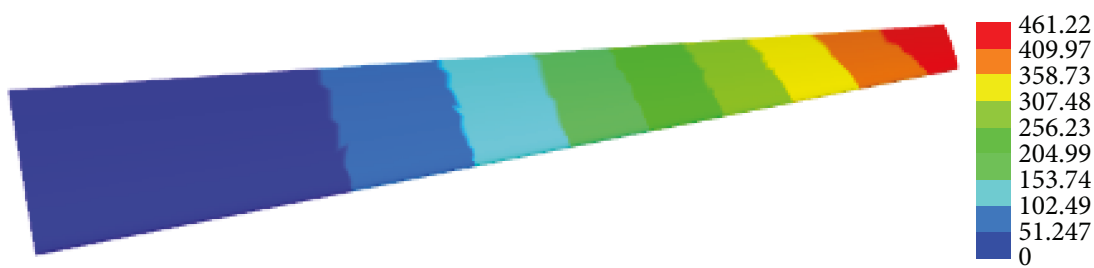

Figure 14: Deformation cloud diagram with the layer sequence being $[0 / 45 / 90 /-45 / 0]_{s}$.

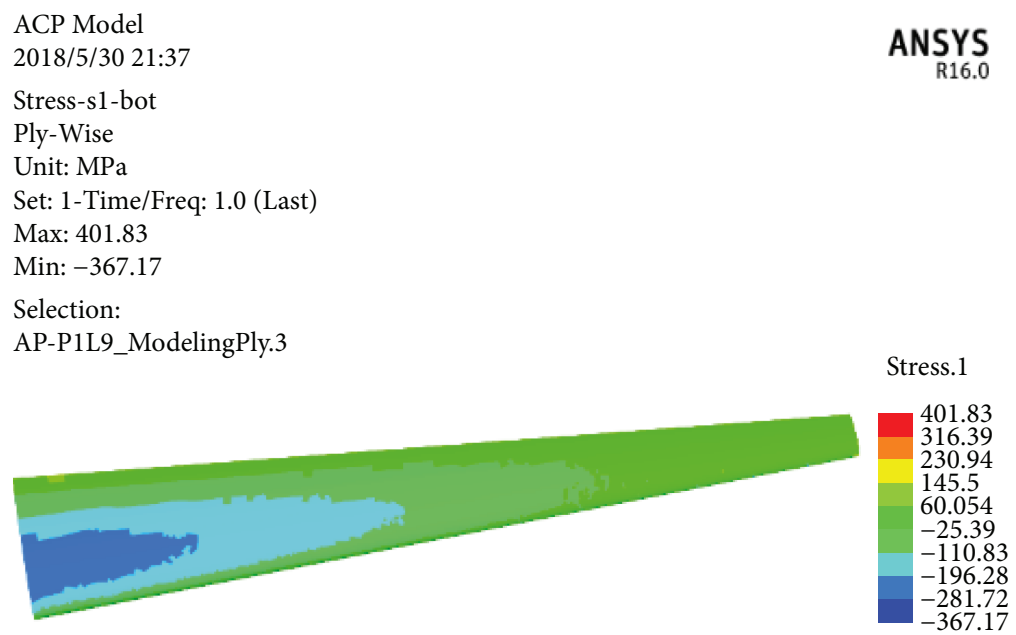

FIgURE 15: Stress cloud diagram of the upper wing with the layer sequence being $[0 / 45 / 90 /-45 / 0]_{s}$.

ACP Model

2018/5/31 10:25

ANSYS

Stress-s1-bot

Ply-Wise

Unit: $\mathrm{MPa}$

Set: 1 -Time/Freq: 1.0 (Last)

Max: 400.36

Min: -368.79

Selection:

AP-P1L7_ModelingPly.7

Stress.1

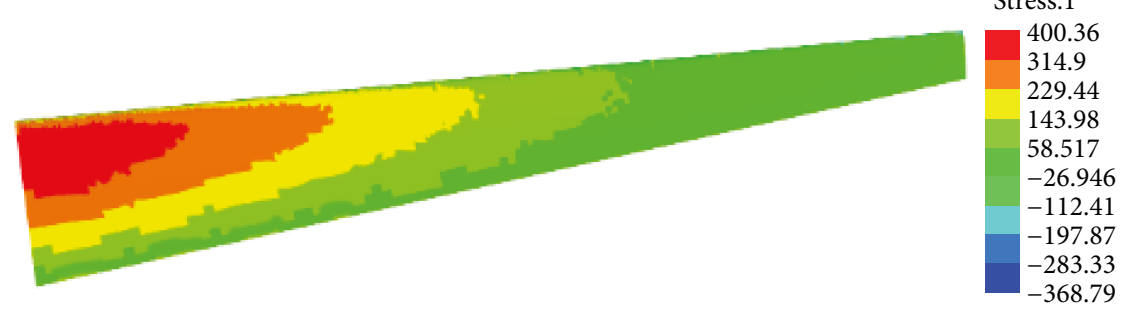

FIGURE 16: Stress cloud diagram of the lower wing with the layer sequence being $[0 / 45 / 90 /-45 / 0]_{s}$. 
ACP Model

2018/5/31 21:56

ANSYS

Deformation-usum

R16.0

Element-Wise

Unit: $\mathrm{mm}$

Set: 1-Time/Freq: 1.0 (Last)

Max: 475.49

Min: 0

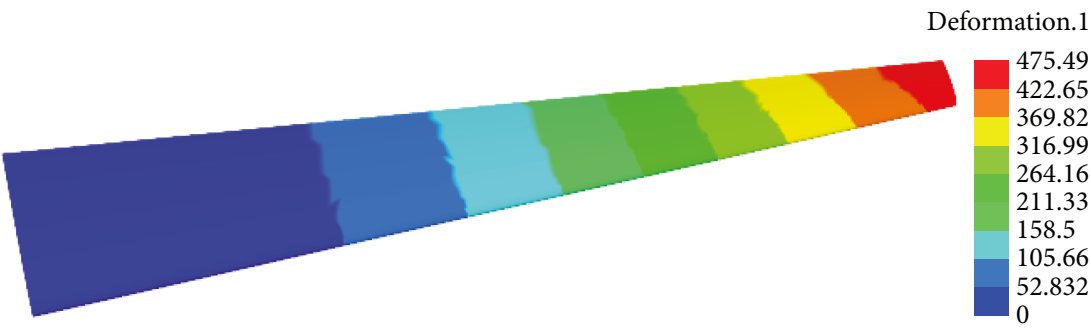

FIGURE 17: Deformation cloud diagram with the layer sequence being $[0 / 45 / 90 /-45 / 0]_{\mathrm{s}}$.

ACP Model

2018/5/31 16:29

ANSYS

Stress-s1-bot

Ply-Wise

Unit: MPa

Set: 1-Time/Freq: 1.0 (Last)

Max: 405.12

Min: -393.14

Selection:

AP-PIL7_ModelingPly.5

Stress.1

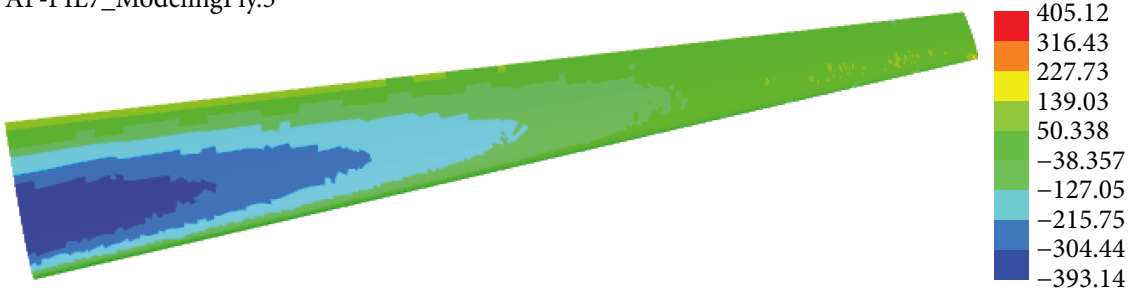

FIGURE 18: Stress cloud diagram of the upper wing with the layer sequence being $[0 / 45 / 90 /-45 / 0]_{s}$.

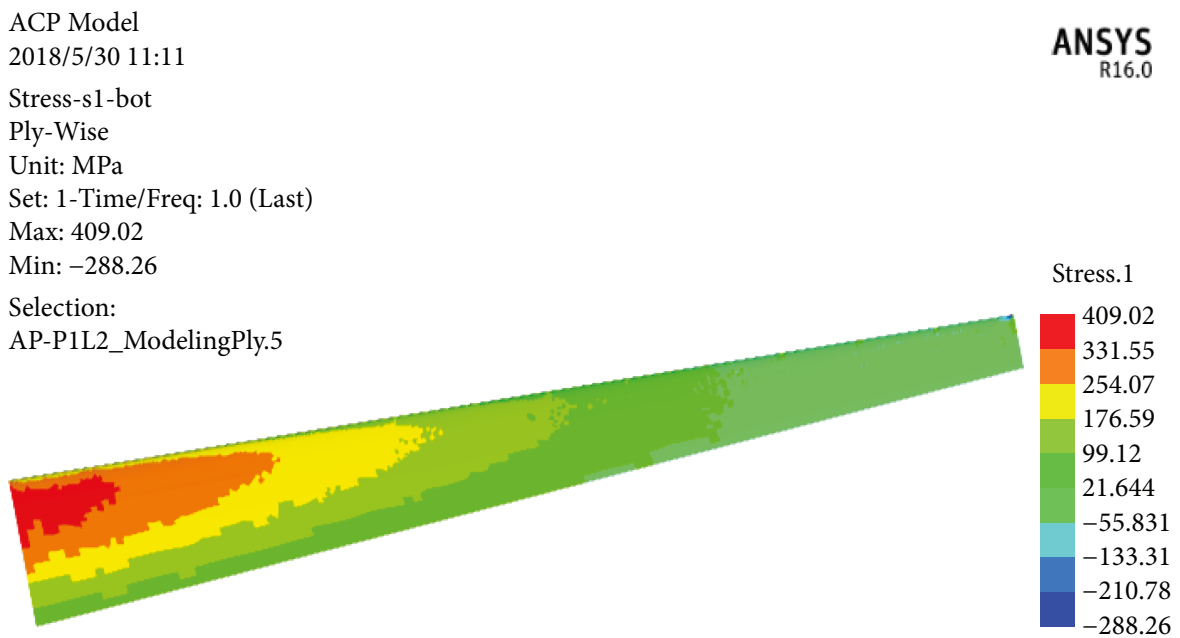

FIGURE 19: Stress cloud diagram of the lower wing with the layer sequence being $[0 / 45 / 90 /-45 / 0]_{s}$. 
ACP Model

2018/5/26 11:32

ANSYS

Deformation-usum

Element-Wise

Unit: $\mathrm{mm}$

Set: 1-Time/Freq: 1.0 (Last)

Max: 446.93

Min: 0

Deformation.1

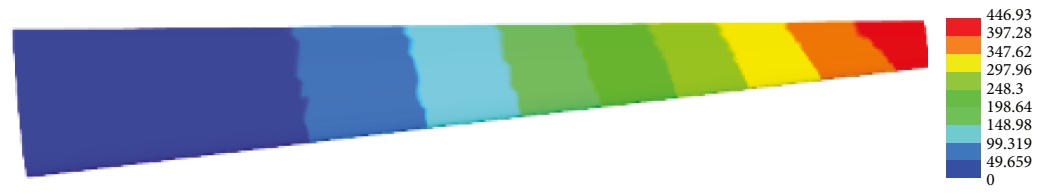

FIgURe 20: Deformation cloud diagram with the layer sequence being [90/45/0/-45/90] $]_{s}$.

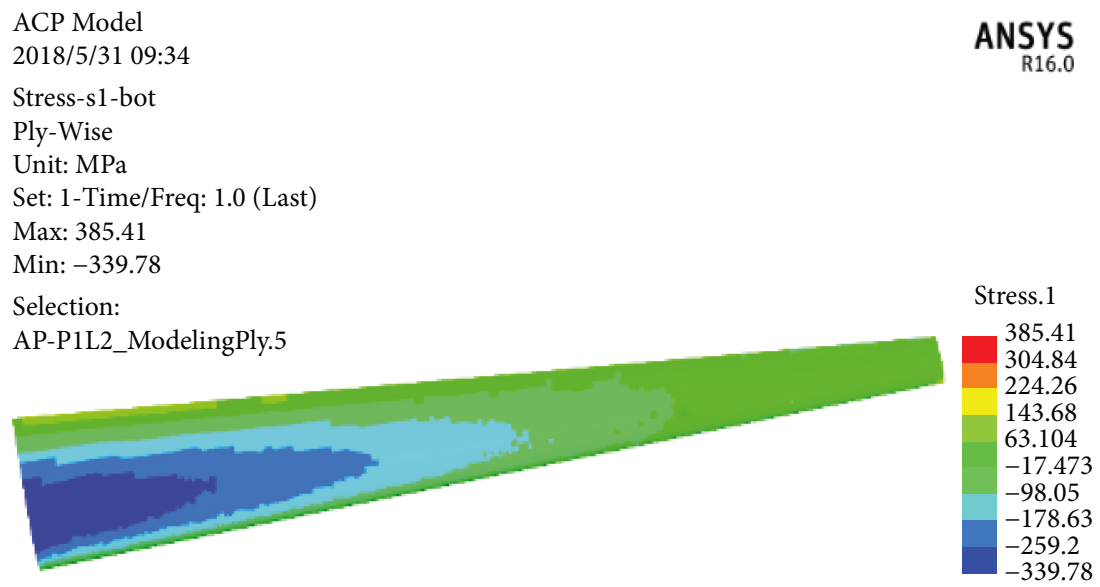

FIGURE 21: Stress cloud diagram of the upper wing with the layer sequence being $[90 / 45 / 0 /-45 / 90]_{S}$.

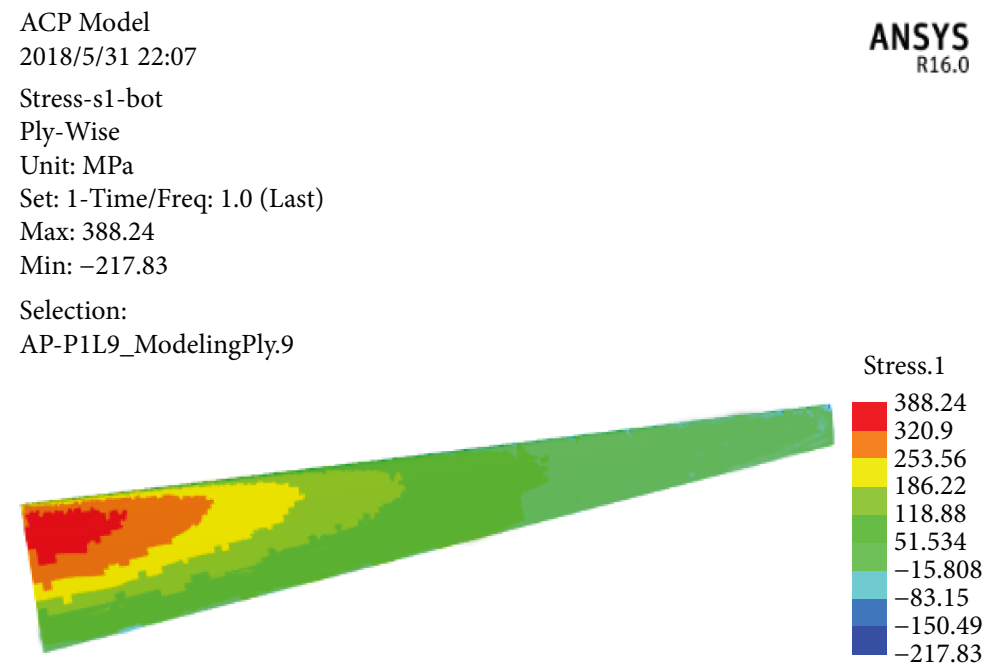

FIGURE 22: Stress cloud diagram of the lower wing with the layer sequence being $[90 / 45 / 0 /-45 / 90]_{S}$.

When the layer ratio is $60 \% / 30 \% / 10 \%$, the deformation and stress cloud diagrams are obtained as Figures 50-52.

It can be obtained that the maximum deformation of the wing is $380.39 \mathrm{~mm}$, the maximum stress of the upper wing is
$344.35 \mathrm{MPa}$, and the maximum stress of the lower wing is 342.01 MPa.

When the layer ratio is $70 \% / 20 \% / 10 \%$, the deformation and stress cloud diagrams are obtained as Figures 53-55. 
ACP Model

2018/5/31 22:16

ANSYS

Deformation-usum

Element-Wise

Unit: $\mathrm{mm}$

Set: 1-Time/Freq: 1.0 (Last)

Max: 451.71

Min: 0

Deformation.1

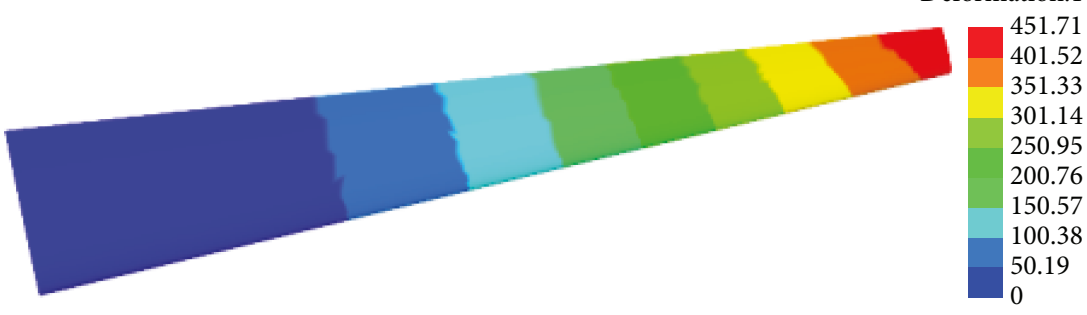

FIGURE 23: Deformation cloud diagram with the layer sequence being $[90 / 0 / 45 / 0 / 90]_{s}$.

ACP Model
2018/5/31 09:19
Stress-s1-bot
Ply-Wise
Unit: MPa
Set: 1 -Time/Freq: 1.0 (Last)
Max: 393.48
Min: -355.23
Selection:
AP-P1L4_ModelingPly.9

ANSYS

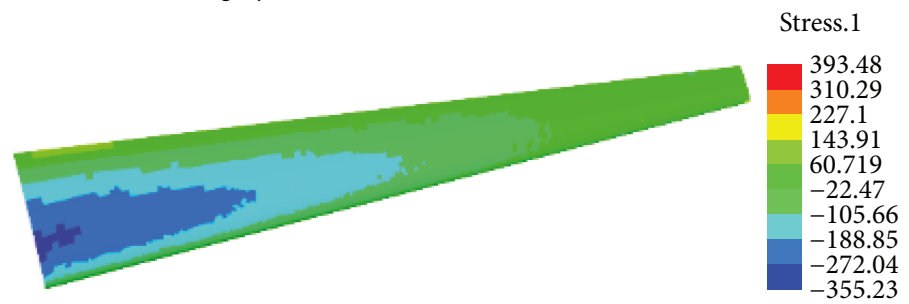

Figure 24: Stress cloud diagram of the upper wing with the layer sequence being $[90 / 0 / 45 / 0 / 90]_{s}$.

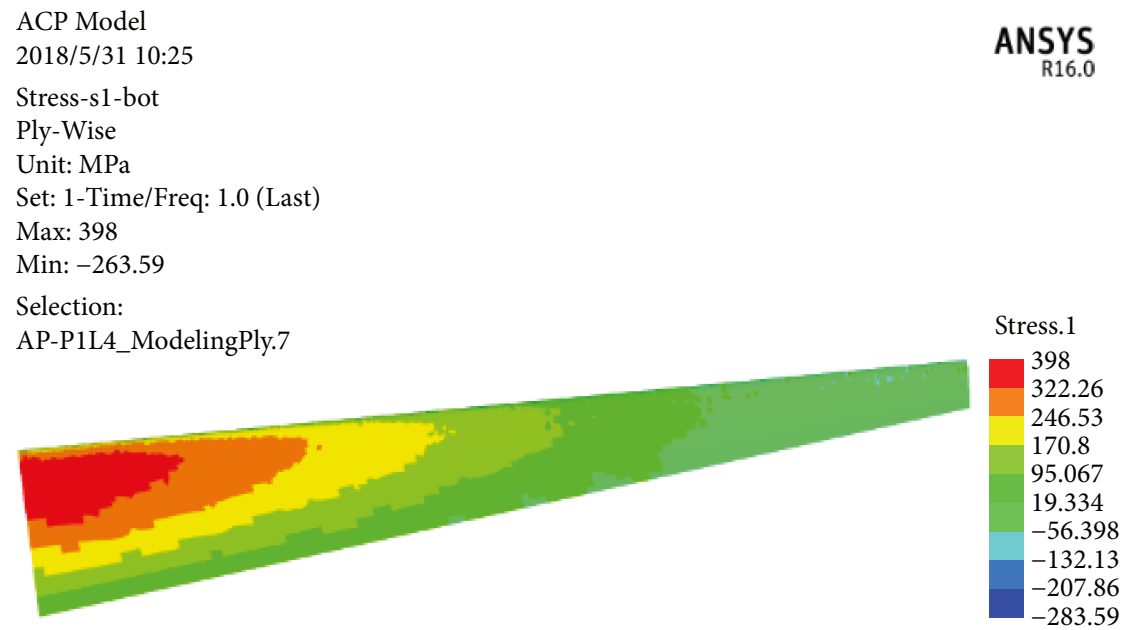

Figure 25: Stress cloud diagram of the lower wing with the layer sequence being $[90 / 0 / 45 / 0 / 90]_{S}$. 
TABLE 6: Structural performance under different layup sequences.

\begin{tabular}{lccccc}
\hline Layer sequences & $\begin{array}{c}\text { Maximum } \\
\text { deformation } \\
(\mathrm{mm})\end{array}$ & $\begin{array}{c}\text { Maximum stress } \\
\text { of the upper } \\
\text { wing }(\mathrm{MPa})\end{array}$ & $\begin{array}{c}\text { Maximum stress } \\
\text { of the lower } \\
\text { wing }(\mathrm{MPa})\end{array}$ & $\begin{array}{c}\text { Maximum Inverse } \\
\text { Reserve Factor of the } \\
\text { upper wing }\end{array}$ & $\begin{array}{c}\text { Maximum Inverse } \\
\text { Reserve Factor of the } \\
\text { lower wing }\end{array}$ \\
\hline$[45 / 90 / 0 / 90 /-45]_{\mathrm{s}}$ & 420.56 & 365.37 & 363.24 & 0.60421 & 0.61564 \\
{$[45 / 0 / 90 / 0-45]_{\mathrm{s}}$} & 427.95 & 366.63 & 367.58 & 0.60732 & 0.61087 \\
{$[0 / 45 / 90 /-45 / 0]_{\mathrm{s}}$} & 461.22 & 401.83 & 400.36 & 0.73685 & 0.73578 \\
{$[0 / 90 / 45 / 90 / 0]_{\mathrm{s}}$} & 475.49 & 405.12 & 409.02 & 0.75397 & 0.75749 \\
{$[90 / 45 / 0 /-45 / 90]_{\mathrm{s}}$} & 446.93 & 385.41 & 388.24 & 0.69798 & 0.67403 \\
{$[90 / 0 / 45 / 0 / 90]_{\mathrm{s}}$} & 451.71 & 393.48 & 398 & 0.68828 & 0.69693 \\
\hline
\end{tabular}

ACP Model

2018/5/27 08:32

ANSYS

Deformation-usum

Element-Wise

Unit: $\mathrm{mm}$

Set: 1 -Time/Freq: 1.0 (Last)

Max: 564.55

Min: 0

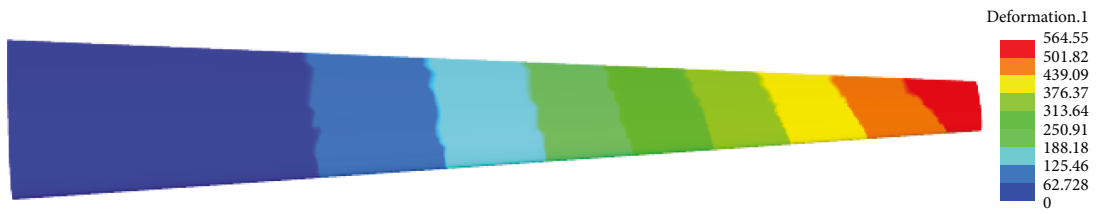

FIgURE 26: Deformation cloud diagram with the layer angle being \pm 45 alone.

ACP Model

2018/5/31 09:43

ANSYS

Stress-s1-bot

Ply-Wise

Unit: MPa

Set: 1-Time/Freq: 1.0 (Last)

Max: 440.19

Min: -398.33

Selection:

AP-P1L9_ModelingPly.4

Stress.1

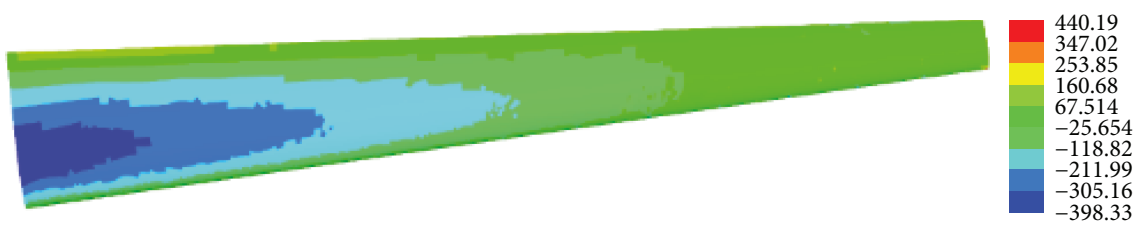

FIGURE 27: Stress cloud diagram of the upper wing with the layer angle being \pm 45 alone.

It can be obtained that the maximum deformation of the wing is $480.24 \mathrm{~mm}$, the maximum stress of the upper wing is $410.35 \mathrm{MPa}$, and the maximum stress of the lower wing is $404.44 \mathrm{MPa}$.

When the layer ratio is $80 \% / 10 \% / 10 \%$, the deformation and stress cloud diagrams are obtained as Figures 56-58.

It can be obtained that the maximum deformation of the wing is $513.53 \mathrm{~mm}$, the maximum stress of the upper wing is 412.4 MPa, and the maximum stress of the lower wing is $421.88 \mathrm{MPa}$.

The obtained results are organized into Table 8 .
By comparing the results in Table 8 , the following conclusions can be drawn:

(1) The deformation of the wing decreases with the increase of the ratio of \pm 45 angle ply, but it is not the more the better. When the ratio exceeds a certain value, the structural strength will decrease gradually

(2) For the skin, when the ratio of the three angles is $60 \% / 30 \% / 10 \%$, the performance of the structure is the best. The maximum upward displacement of the wingtip is $0.38039 \mathrm{~m}$, the maximum stress of the upper skin layer is $344.35 \mathrm{MPa}$, and the maximum stress of the lower skin layer is $342.01 \mathrm{MPa}$ 
ACP Model

2018/5/31 09:48

ANSYS

Stress-s1-bot

Ply-Wise

Unit: $\mathrm{MPa}$

Set: 1-Time/Freq: 1.0 (Last)

Max: 447.24

Min: -619.98

Selection:

AP-P1L4_ModelingPly.8

Stress.1

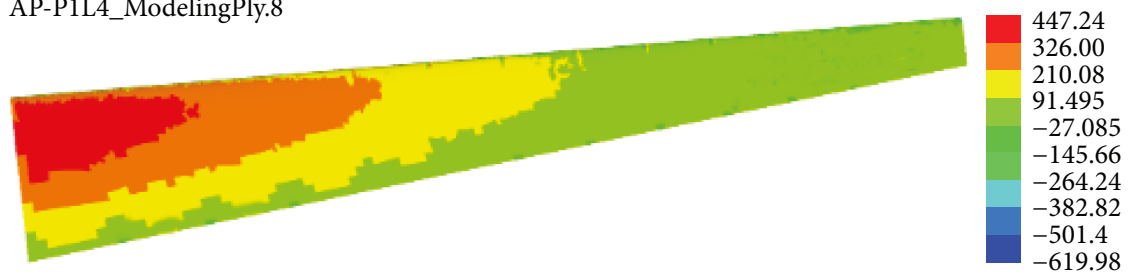

FIgURE 28: Stress cloud diagram of the lower wing with the layer angle being \pm 45 alone.

ACP Model

2018/5/27 10:42

ANSYS

Deformation-usum

Element-Wise

Unit: $\mathrm{mm}$

Set: 1 -Time/Freq: 1.0 (Last)

Max: 493.56

Min: 0

Deformation.1

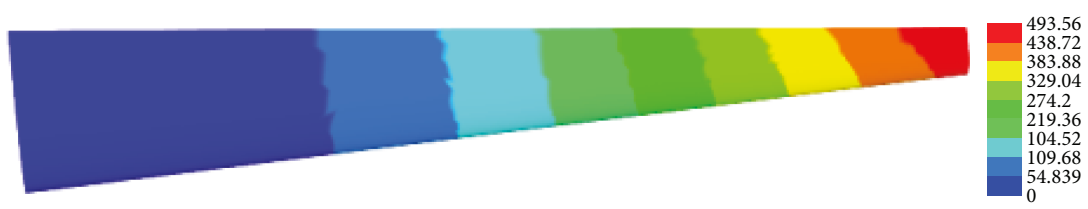

Figure 29: Deformation cloud diagram with the layer angle being 45 and 0.

ACP Model

2018/5/31 08:42

ANSYS

Stress-s1-bot

Ply-Wise

Unit: $\mathrm{MPa}$

Set: 1-Time/Freq: 1.0 (Last)

Max: 449.53

Min: -423.61

Selection:

AP-P1L4_ModelingPly.3

Stress. 1

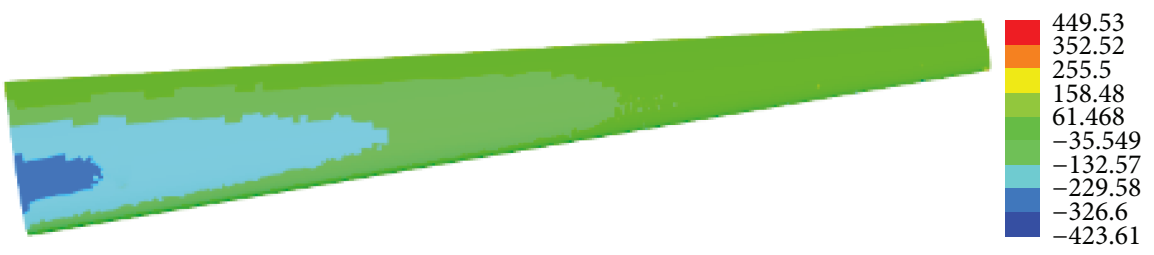

FIGURE 30: Stress cloud diagram of the upper wing with the layer angle being 45 and 0. 
ACP Model

2018/5/31 09:47

ANSYS

Stress-s1-bot

Ply-Wise

Unit: $\mathrm{MPa}$

Set: 1-Time/Freq: 1.0 (Last)

Max: 434.73

Min: -309.77

Selection:

AP-P1L4_ModelingPly.7

Stress. 1

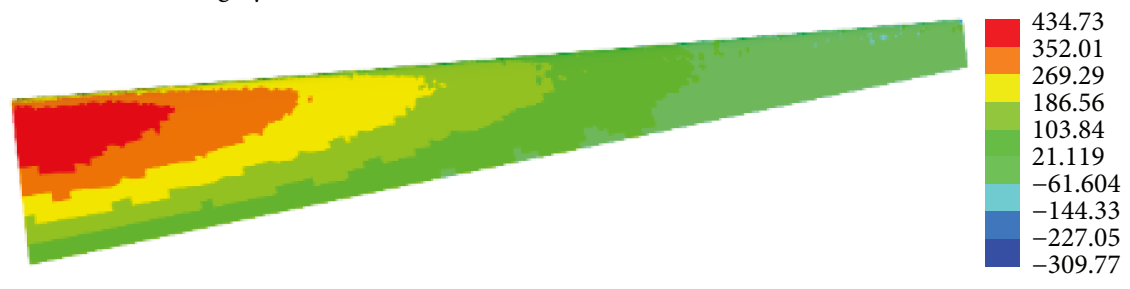

FIGURE 31: Stress cloud diagram of the lower wing with the layer angle being 45 and 0.

ACP Model

2018/5/27 18:45

ANSYS

Deformation-usum

Element-Wise

Unit: $\mathrm{mm}$

Set: 1 -Time/Freq: 1.0 (Last)

Max: 456.47

Min: 0

Deformation.1

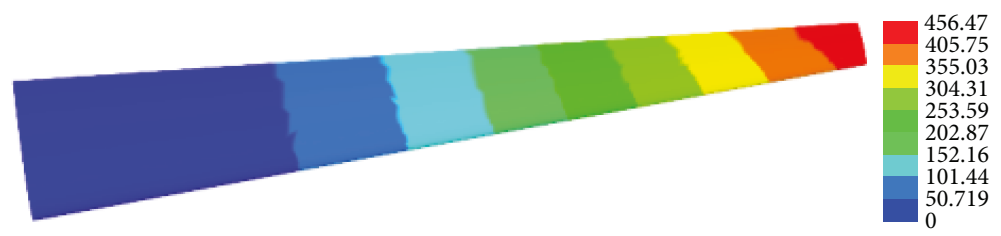

FIgURe 32: Deformation cloud diagram with the layer angle being 90 and 0.

ACP Model

2018/5/31 08:43

ANSYS

Stress-s1-bot

R16.0

Ply-Wise

Unit: $\mathrm{MPa}$

Set: 1-Time/Freq: 1.0 (Last)

Max: 420.91

Min: -389.75

Selection:

AP-P1L7_ModelingPly.3

Stress.1

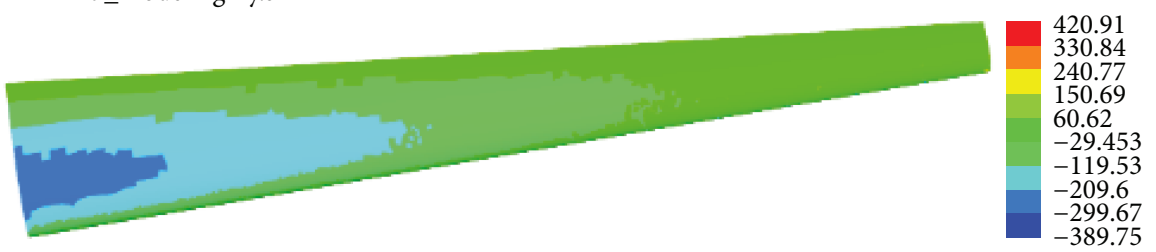

FIGURE 33: Stress cloud diagram of the upper wing with the layer angle being 90 and 0. 
ACP Model

2018/5/31 10:00

ANSYS

Stress-s1-bot

R16.0

Ply-Wise

Unit: $\mathrm{MPa}$

Set: 1-Time/Freq: 1.0 (Last)

Max: 420.5

Min: -445.24

Selection:

AP-P1L9_ModelingPly.7

Stress.1

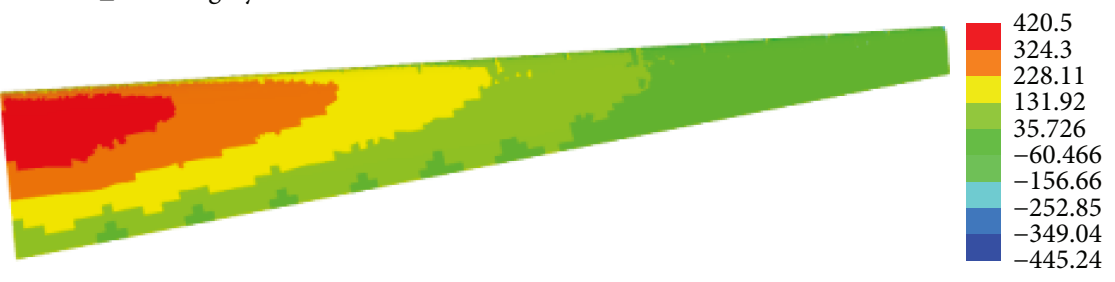

FIGURE 34: Stress cloud diagram of the lower wing with the layer angle being 90 and 0 .

ACP Model

2018/5/27 09:24

ANSYS

Deformation-usum

R16.0

Element-Wise

Unit: $\mathrm{mm}$

Set: 1 -Time/Freq: 1.0 (Last)

Max: 485

Min: 0

Deformation.1

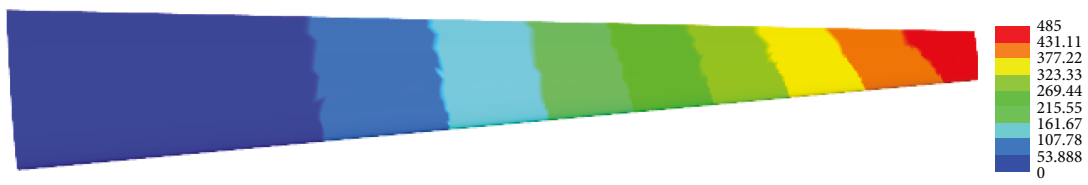

FiguRe 35: Deformation cloud diagram with the layer angle being 45 and 90.

ACP Model

2018/5/31 08:57

ANSYS

Stress-s1-bot

R16.0

Ply-Wise

Unit: $\mathrm{MPa}$

Set: 1-Time/Freq: 1.0 (Last)

Max: 434.27

Min: -402.12

Selection:

AP-P1L7_ModelingPly.3

Stress. 1

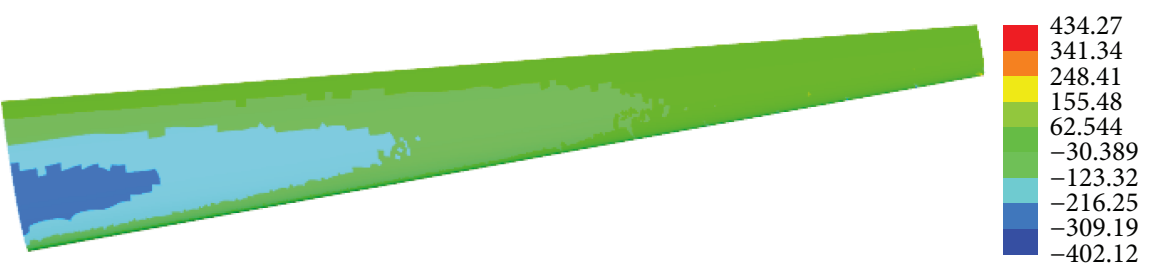

FIgURE 36: Stress cloud diagram of the upper wing with the layer angle being 45 and 90. 
ACP Model

2018/5/31 10:17

ANSYS

Stress-s1-bot

Ply-Wise

Unit: MPa

Set: 1-Time/Freq: 1.0 (Last)

Max: 432.86

Min: -458.33

Selection:

AP-P1L9_ModelingPly.7

Stress.1

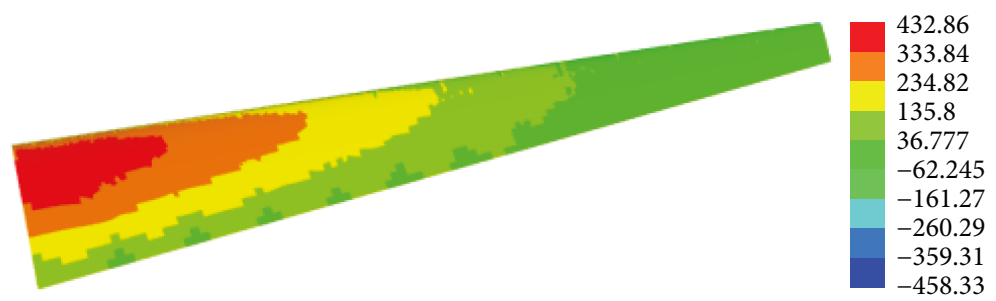

Figure 37: Stress cloud diagram of the lower wing with the layer angle being 45 and 90.
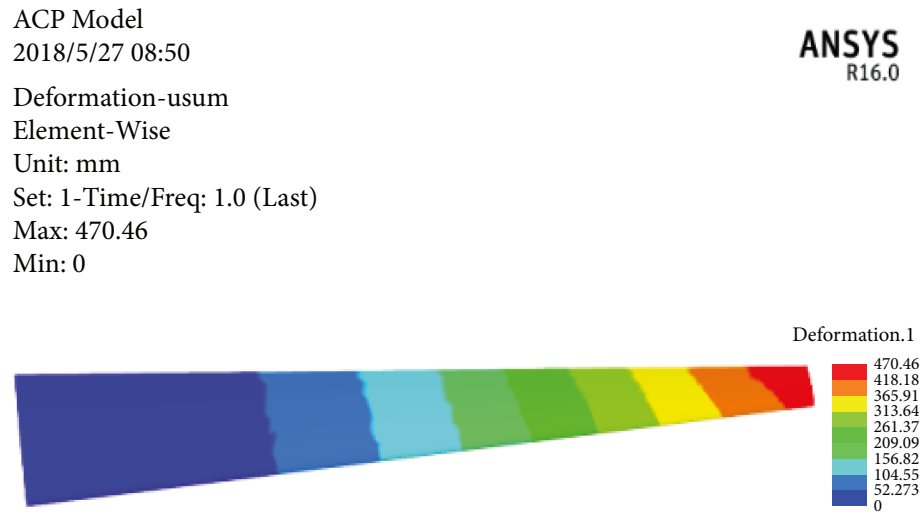

Figure 38: Deformation cloud diagram with the layer angle being \pm 45 and 90 .

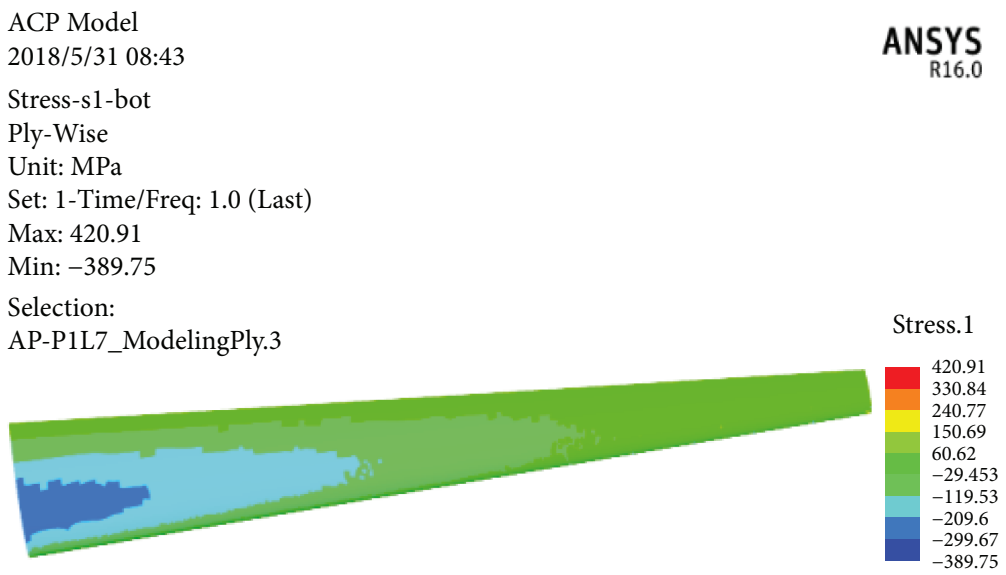

Figure 39: Stress cloud diagram of the upper wing with the layer angle being \pm 45 and 90 . 
ACP Model

2018/5/31 10:31

ANSYS

Stress-s1-bot

Ply-Wise

Unit: $\mathrm{MPa}$

Set: 1-Time/Freq: 1.0 (Last)

Max: 416.36

Min: -296.68

Selection:

AP-P1L4_ModelingPly.7

Stress.1

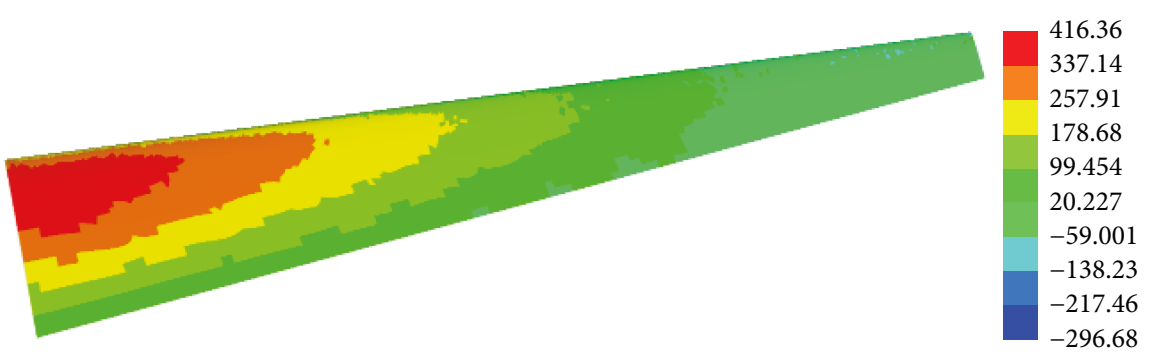

Figure 40: Stress cloud diagram of the lower wing with the layer angle being \pm 45 and 90 .

TABLE 7: Structural performance of different ply angles.

\begin{tabular}{lccccc}
\hline Ply angle & $\begin{array}{c}\text { Maximum } \\
\text { deformation (mm) }\end{array}$ & $\begin{array}{c}\text { Maximum stress } \\
\text { of the upper wing (MPa) }\end{array}$ & $\begin{array}{c}\text { Maximum stress } \\
\text { of the lower wing (MPa) }\end{array}$ & $\begin{array}{c}\text { Maximum Inverse } \\
\text { Reserve Factor of the } \\
\text { upper wing }\end{array}$ & $\begin{array}{c}\text { Maximum Inverse } \\
\text { Reserve Factor of the } \\
\text { lower wing }\end{array}$ \\
\hline \pm 45 & 564.55 & 440.19 & 447.24 & 0.86126 & 0.85697 \\
$45 / 0$ & 493.56 & 449.53 & 434.73 & 0.83945 & 0.80798 \\
$90 / 0$ & 456.47 & 420.91 & 420.5 & 0.82485 & 0.76403 \\
$45 / 90$ & 485 & 434.27 & 432.86 & 0.73191 & 0.77961 \\
$\pm 45 / 90$ & 470.46 & 420.91 & 416.36 & 0.60421 & 0.72532 \\
$\pm 45 / 0 / 90$ & 420.56 & 365.37 & 363.24 & 0.61564 \\
\hline
\end{tabular}

ACP Model

2018/5/27 10:23

ANSYS

Deformation-usum

R16.0

Element-Wise

Unit: $\mathrm{mm}$

Set: 1-Time/Freq: 1.0 (Last)

Max: 523.99

Min: 0

Deformation.1

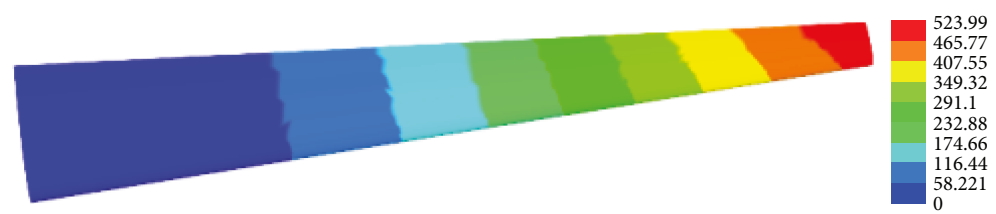

FIGURE 41: Deformation cloud diagram with the layer ratio being 10\%/10\%/80\%.

\section{Comparison of the Wing Structure of Different Material Types}

The aluminum alloy is the most commonly used material for wing manufacturing before the use of composite materials.
Later, composite materials have become popular aviation materials. In order to prove that composite materials have better performance than aluminum alloy materials, the fullcomposite wing and full-metal wing are compared with the semicomposite wing in this paper. 
ACP Model

2018/5/31 16:29

ANSYS

Stress-s1-bot

Ply-Wise

Unit: MPa

Set: 1 - Time/Freq: 1.0 (Last)

Max: 434.1

Min: -393.58

Selection:

AP-P1L4_Modeling Ply.5

Stress.1

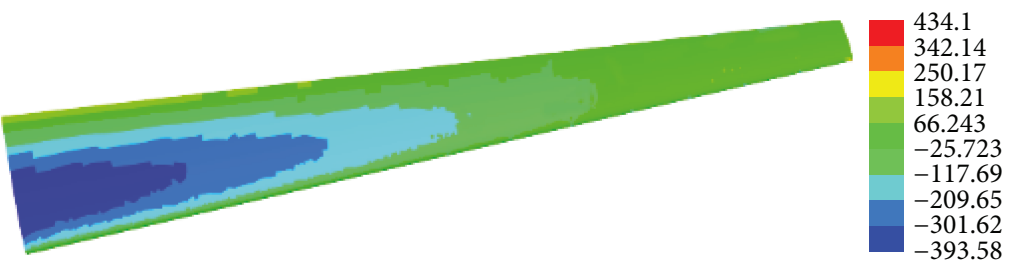

FIGURE 42: Stress cloud diagram of the upper wing with the layer ratio being 10\%/10\%/80\%.

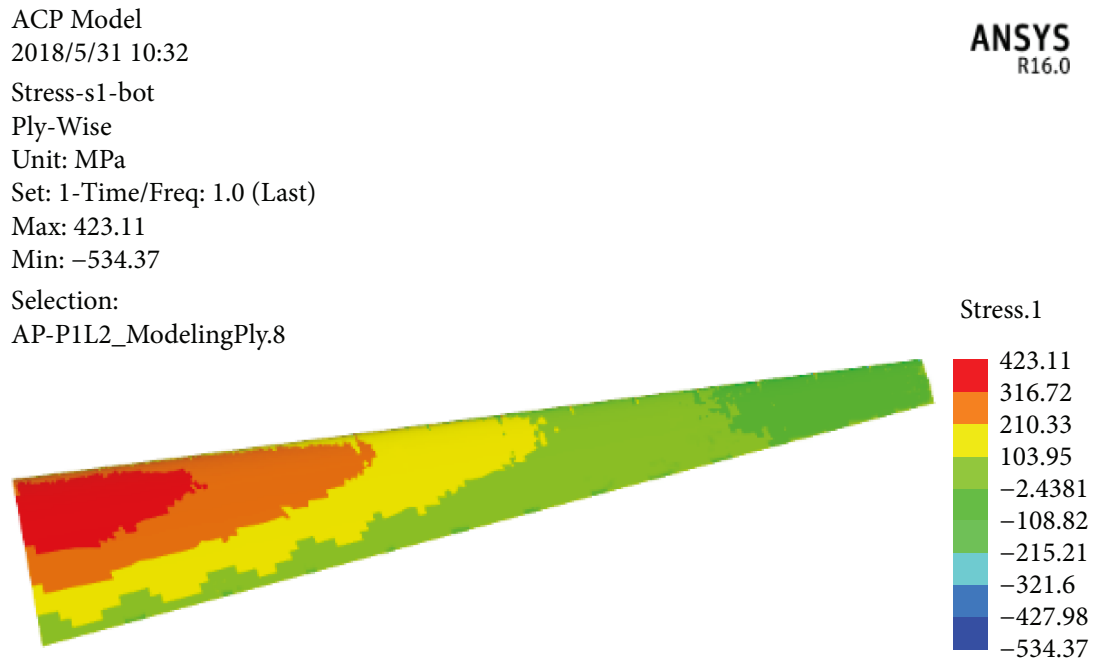

Figure 43: Stress cloud diagram of the lower wing with the layer ratio being 10\%/10\%/80\%.

ACP Model

2018/5/27 07:41

ANSYS

Deformation-usum

R16.0

Element-Wise

Unit: $\mathrm{mm}$

Set: 1-Time/Freq: 1.0 (Last)

Max: 498.69

Min: 0

Deformation.1

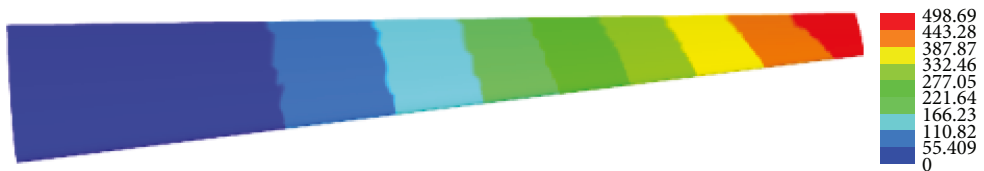

FIGURE 44: Deformation cloud diagram with the layer ratio being 20\%/20\%/60\%. 
ACP Model

2018/5/31 09:18

ANSYS

Stress-s1-bot

Ply-Wise

Unit: MPa

Set: 1-Time/Freq: 1.0 (Last)

Max: 414.68

Min: -374.08

Selection:

AP-P1L2_ModelingPly.4

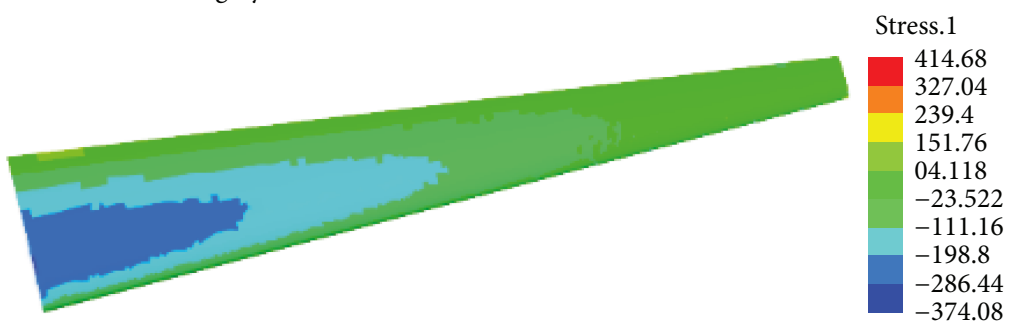

Figure 45: Stress cloud diagram of the upper wing with the layer ratio being 20\%/20\%/60\%.

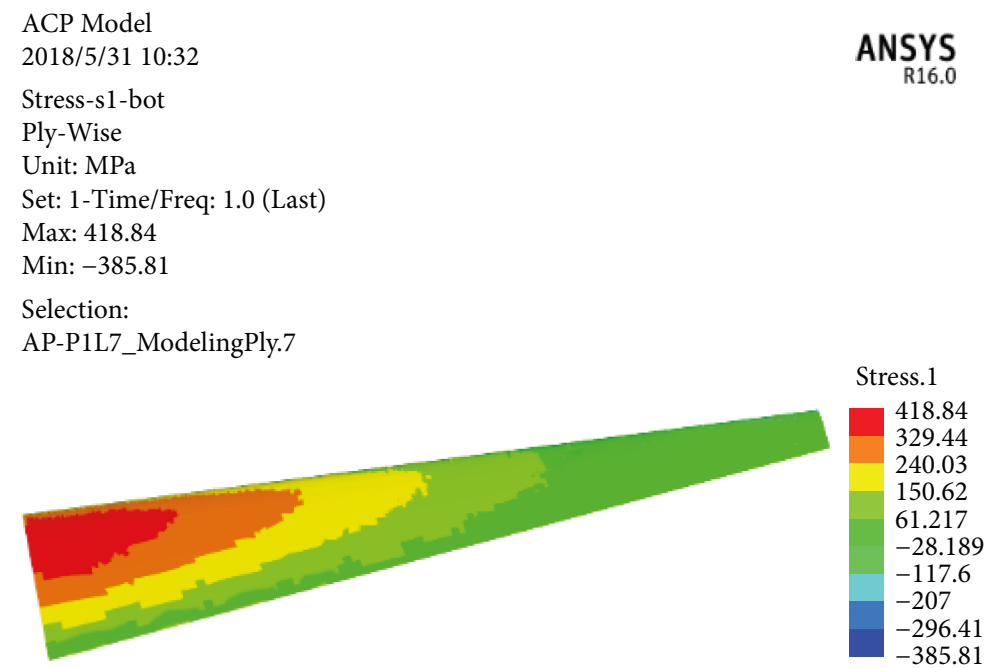

FIGURE 46: Stress cloud diagram of the lower wing with the layer ratio being 20\%/20\%/60\%.

ACP Model

2018/5/31 14:59

ANSYS

Deformation-usum

Element-Wise

Unit: $\mathrm{mm}$

Set: 1-Time/Freq: 1.0 (Last)

Max: 456.47

Min: 0

Deformation.1

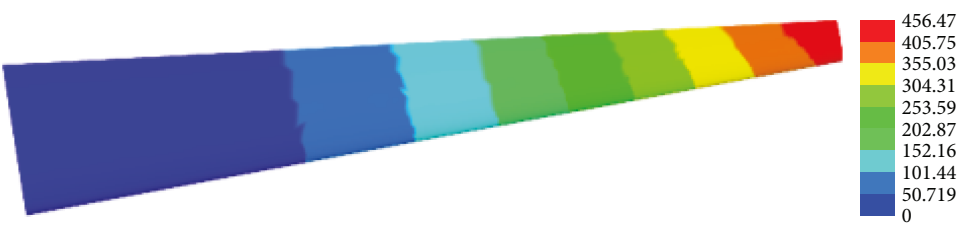

FIGURE 47: Deformation cloud diagram with the layer ratio being 30\%/60\%/10\%. 
ACP Model

2018/5/31 16:28

ANSYS

Stress-s1-bot

Ply-Wise

Unit: MPa

Set: 1-Time/Freq: 1.0 (Last)

Max: 405.12

Min: -393.14

Selection:

Stress.1

AP-P1L7_ModelingPly.5

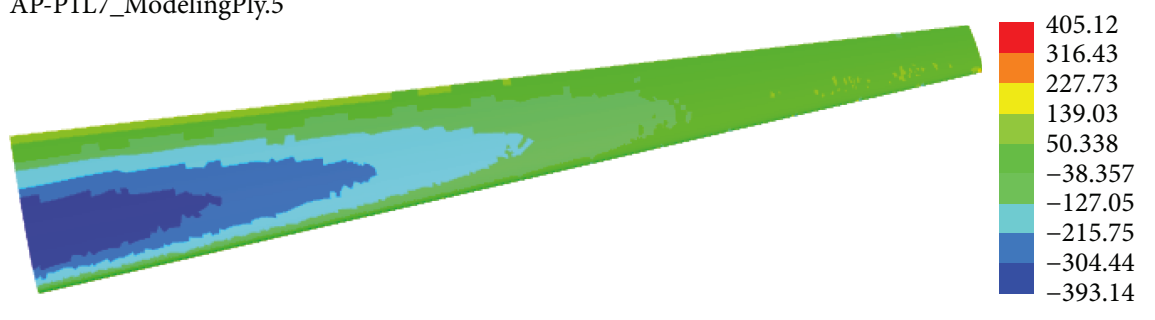

FIGURE 48: Stress cloud diagram of the upper wing with the layer ratio being 30\%/60\%/10\%.

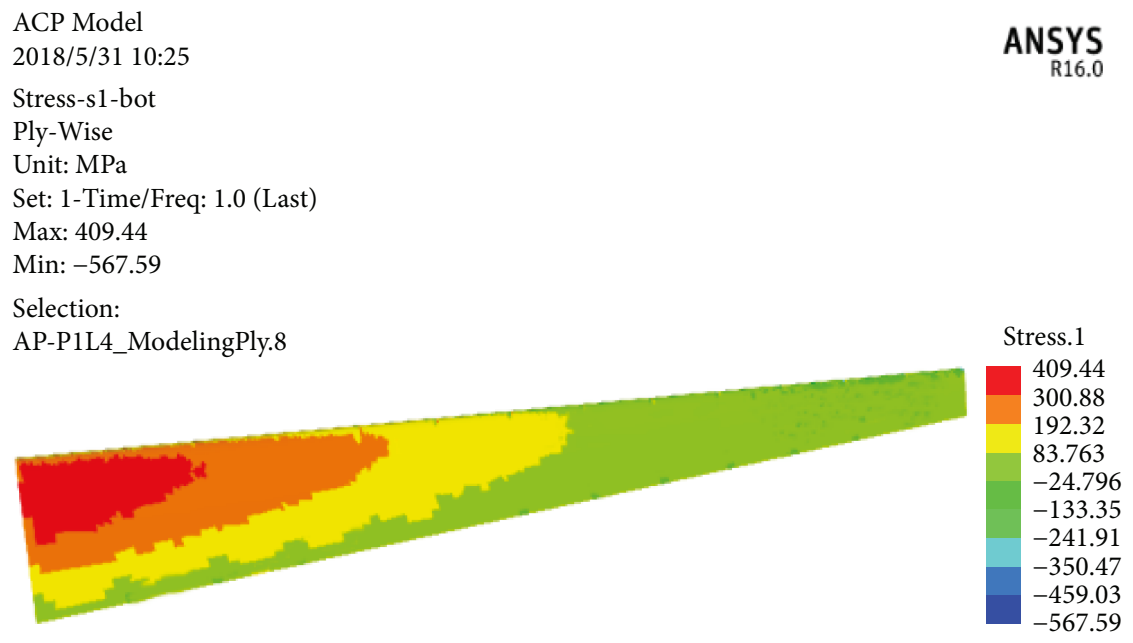

FIGURE 49: Stress cloud diagram of the lower wing with the layer ratio being 30\%/60\%/10\%.

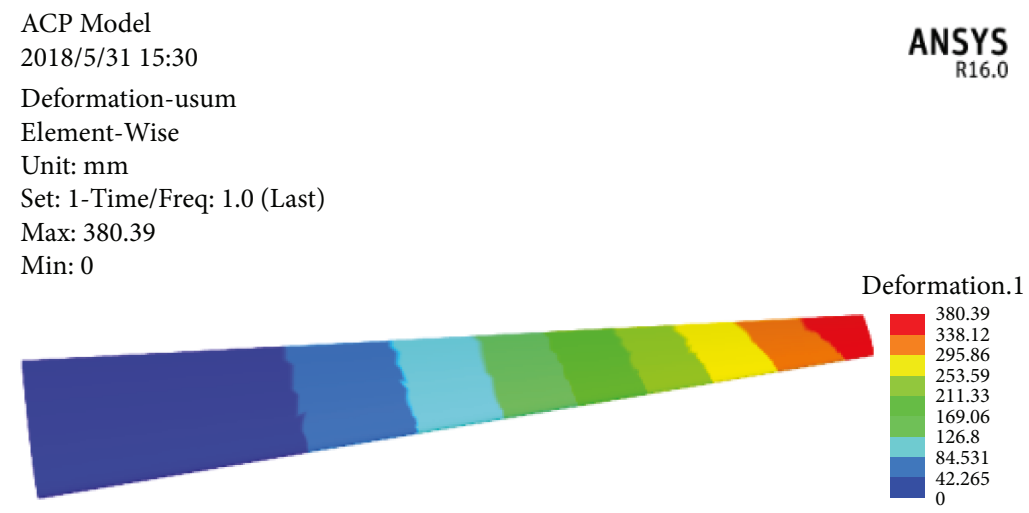

FIgURE 50: Deformation cloud diagram with the layer ratio being 60\%/30\%/10\%.

6.1. Full-Metal Wing Structure. The static analysis of the fullmetallic wing structure is carried out under the same loading condition, and the deformation and stress cloud diagrams are obtained as Figures 59 and 60.
6.2. Full-Composite Wing Structure. For the composite wing structure designed in this paper, due to the characteristics of the beam structure, the front and back beams are not the composite structure. In this section, the front and back beams 
ACP Model

2018/5/31 09:34

ANSYS

Stress-s1-bot

Ply-Wise

Unit: MPa

Set: 1-Time/Freq: 1.0 (Last)

Max: 344.35

Min: -334.17

Selection:

AP-P1L7_ModelingPly.5

Stress.1

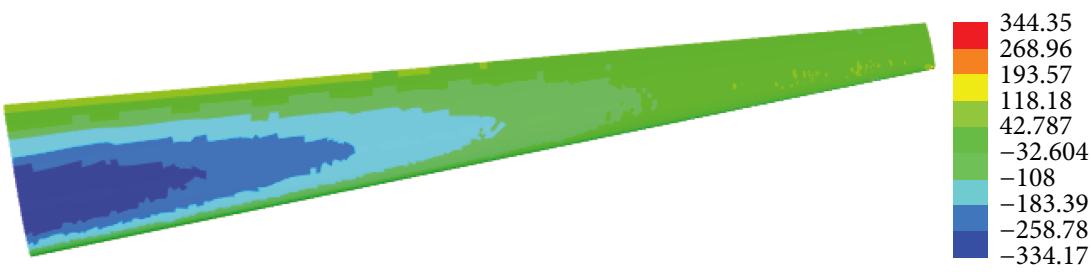

FIGURE 51: Stress cloud diagram of the upper wing with the layer ratio being 60\%/30\%/10\%.

ACP Model

2018/5/31 15:05

ANSYS

Stress-s1-bot

Ply-Wise

Unit: $\mathrm{MPa}$

Set: 1-Time/Freq: 1.0 (Last)

Max: 342.01

Min: -165.62

Selection:

AP-P1L2_ModelingPly.13

Stress. 1

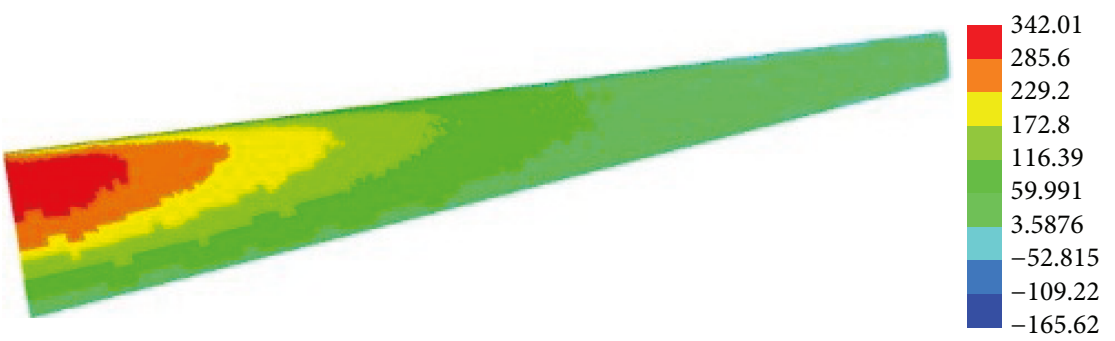

FIGURE 52: Stress cloud diagram of the lower wing with the layer ratio being 60\%/30\%/10\%.

ACP Model

2018/5/31 14:51

ANSYS

Deformation-usum

Element-Wise

Unit: $\mathrm{mm}$

Set: 1-Time/Freq: 1.0 (Last)

Max: 480.24

Min: 0

Deformation.1

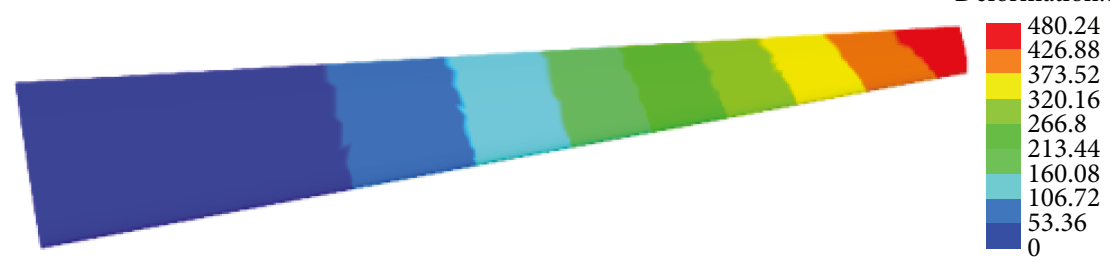

Figure 53: Deformation cloud diagram with the layer ratio being 70\%/20\%/10\%. 
ACP Model

2018/5/31 09:43

ANSYS

Stress-s1-bot

Ply-Wise

Unit: MPa

Set: 1-Time/Freq: 1.0 (Last)

Max: 410.35

Min: -361.77

Selection:

AP-P1L2_ModelingPly.5

Stress.1

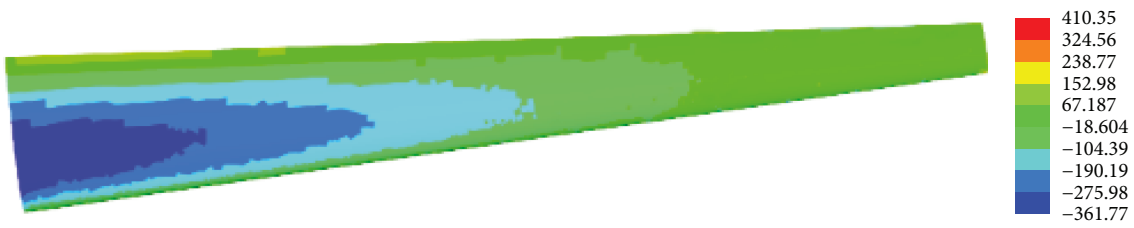

FigURE 54: Stress cloud diagram of the upper wing with the layer ratio being 70\%/20\%/10\%.

ACP Model

2018/5/31 10:25

ANSYS

Stress-s1-bot

Ply-Wise

Unit: $\mathrm{MPa}$

Set: 1-Time/Freq: 1.0 (Last)

Max: 404.44

Min: -510.79

Selection:

Stress. 1

AP-P1L2_ModelingPly.8

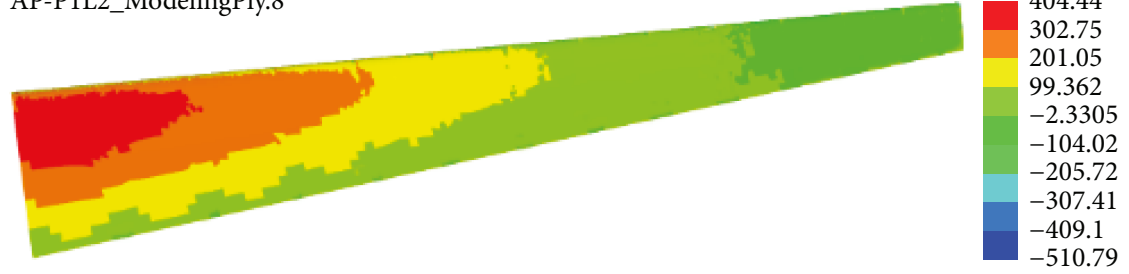

Figure 55: Stress cloud diagram of the lower wing with the layer ratio being 70\%/20\%/10\%.

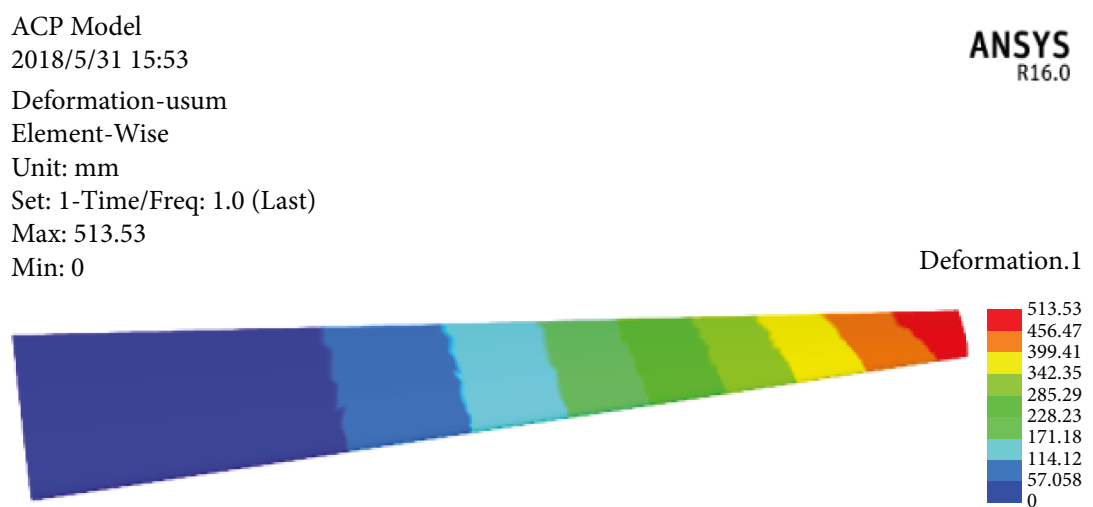

FIgURE 56: Deformation cloud diagram with the layer ratio being $80 \% / 10 \% / 10 \%$.

are separately layered as well, and the web adopts the $45^{\circ}$ layup to bear the shearing force. The layup of each layer of the upper and lower flanges is [45/90/0/90/-45] symmetrically, and the static analysis of the full-composite wing is carried out. The deformation and stress cloud diagrams are obtained as Figures 61-63.
The obtained results of these materials are organized into Table 9.

It can be seen from the data in Table 9 that the mechanical properties of the composite structure are obviously superior to those of the metal structure. Under the same load, the maximum deformation difference of the 
ACP Model

2018/5/31 09:57

ANSYS

Stress-s1-bot

Ply-Wise

Unit: $\mathrm{MPa}$

Set: 1-Time/Freq: 1.0 (Last)

Max: 412.4

Min: -373.91

Selection:

AP-P1L4_ModelingPly.5

Stress.1

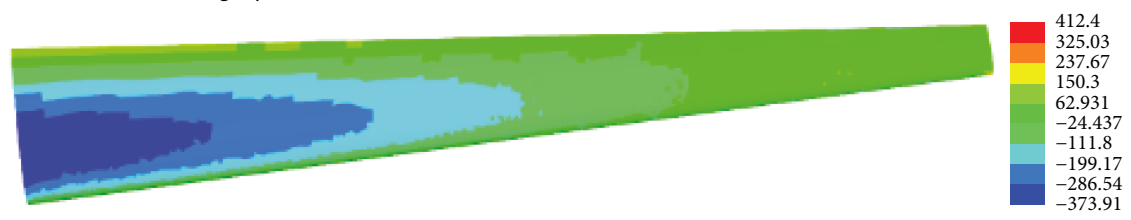

Figure 57: Stress cloud diagram of the upper wing with the layer ratio being $80 \% / 10 \% / 10 \%$.

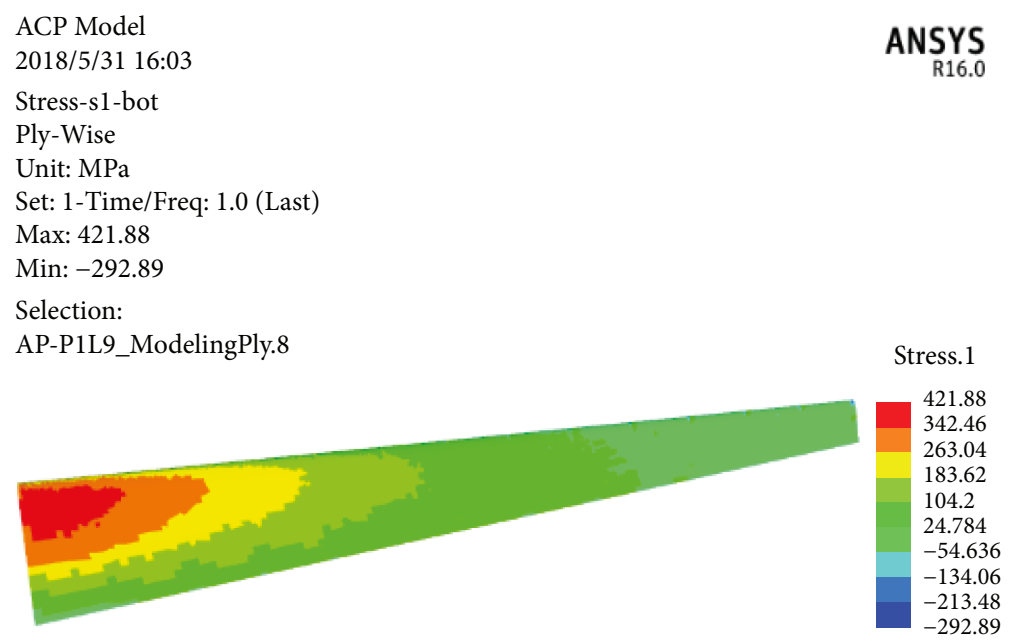

FIgURE 58: Stress cloud diagram of the lower wing with the layer ratio being $80 \% / 10 \% / 10 \%$.

TABLE 8: Structural performance of different ply ratios.

\begin{tabular}{lccccc}
\hline Ply ratio & $\begin{array}{c}\text { Maximum } \\
\text { deformation }(\mathrm{mm})\end{array}$ & $\begin{array}{c}\text { Maximum stress } \\
\text { of the upper } \\
\text { wing (MPa) }\end{array}$ & $\begin{array}{c}\text { Maximum stress } \\
\text { of the lower } \\
\text { wing (MPa) }\end{array}$ & $\begin{array}{c}\text { Maximum Inverse } \\
\text { Reserve Factor of the } \\
\text { upper wing }\end{array}$ & $\begin{array}{c}\text { Maximum Inverse } \\
\text { Reserve Factor of the } \\
\text { lower wing }\end{array}$ \\
\hline $10 \% / 10 \% / 80 \%$ & 523.99 & 434.1 & 423.11 & 0.79962 & 0.79633 \\
$20 \% / 20 \% / 60 \%$ & 498.69 & 414.68 & 418.84 & 0.74143 & 0.73968 \\
$30 \% / 60 \% / 10 \%$ & 456.47 & 405.12 & 409.44 & 0.68891 & 0.68746 \\
$40 \% / 40 \% / 20 \%$ & 420.56 & 365.37 & 363.24 & 0.60421 & 0.61564 \\
$60 \% / 30 \% / 10 \%$ & 380.39 & 344.35 & 342.01 & 0.59786 & 0.57493 \\
$70 \% / 20 \% / 10 \%$ & 480.24 & 410.35 & 404.44 & 0.69452 & 0.70541 \\
$80 \% / 10 \% / 10 \%$ & 513.53 & 412.4 & 421.88 & 0.76534 & 0.75482 \\
$100 \% / 0 \% / 0 \%$ & 564.55 & 440.19 & 447.24 & 0.83126 & 0.85697 \\
\hline
\end{tabular}

wingtip can reach $44.83 \%$ and the mass difference can reach $42.45 \%$, which proves that the use of composite material can effectively reduce the deformation of the wing, and the weight of the composite wing is significantly lower with respect to the weight of the metallic wing. So it is concluded that the advantage of composite material is incomparable.

\section{Conclusions}

This paper is aimed at designing a large aspect ratio composite wing and confirming the advantages of the composite wing. At first, the aerodynamic analysis of the wing is conducted, and the design indexes of high aspect ratio wing are preliminarily formulated. Then, the structural finite element 
G: Static Structural

Total Deformation

Type: Total Deformation

Unit: $\mathrm{mm}$

Time: 1

2018/6/11 12:11

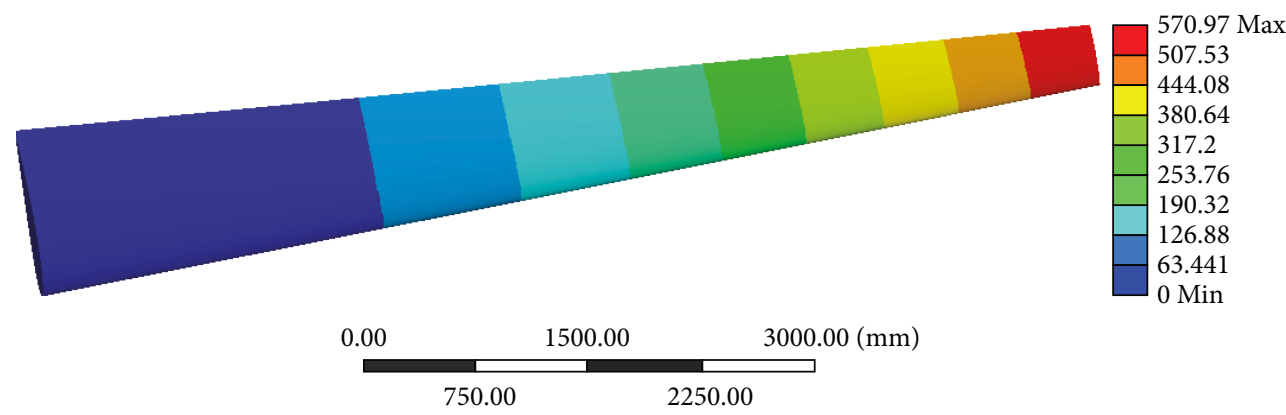

FIgURE 59: Deformation cloud diagram of full-metallic wing.

G: Static Structural

Equivalent Stress

Type: Equivalent (von-Mises) Stress

Unit: MPa

Time: 1

2018/6/11 11:52

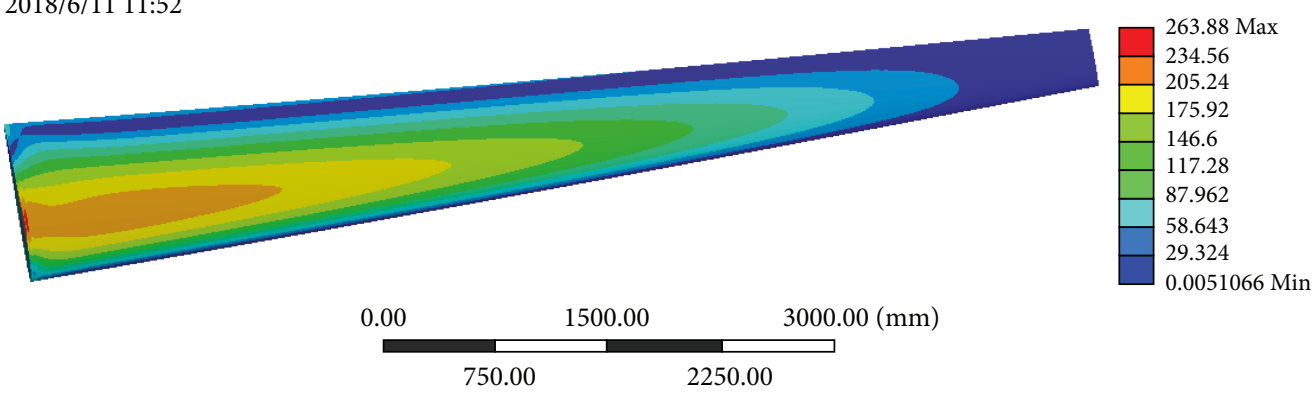

FIGURE 60: Stress cloud diagram of full-metallic wing.

ACP Model

2018/6/11 11:56

ANSYS

Deformation-usum

Element-Wise

Unit: $\mathrm{mm}$

Set: 1-Time/Freq: 1.0 (Last)

Max: 315

Min: 0

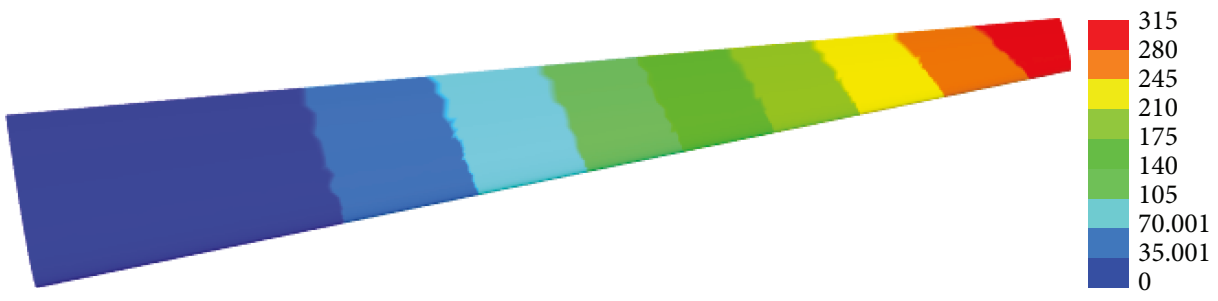

Figure 61: Deformation cloud diagram of full-composite wing. 
ACP Model

2018/5/31 22:10

ANSYS

Stress-s1-bot

Ply-Wise

Unit: MPa

Set: 1 -Time/Freq: 1.0 (Last)

Max: 309.34

Min: -282.66

Selection:

AP-P1L9_ModelingPly.3

Stress.1

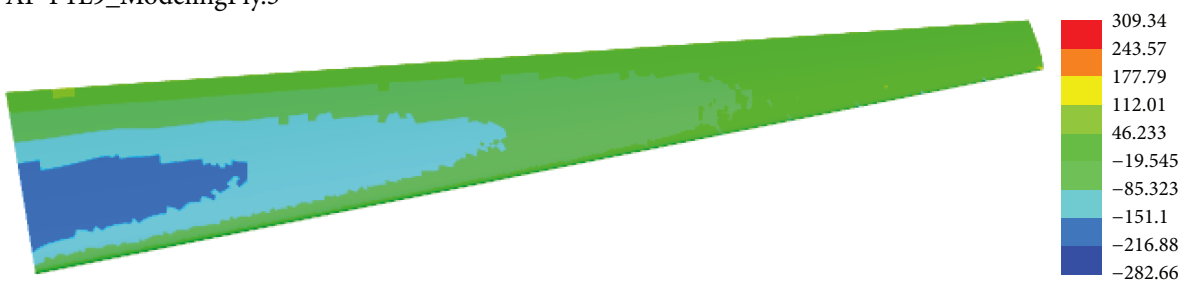

FIgURE 62: Stress cloud diagram of the upper wing with full composite.

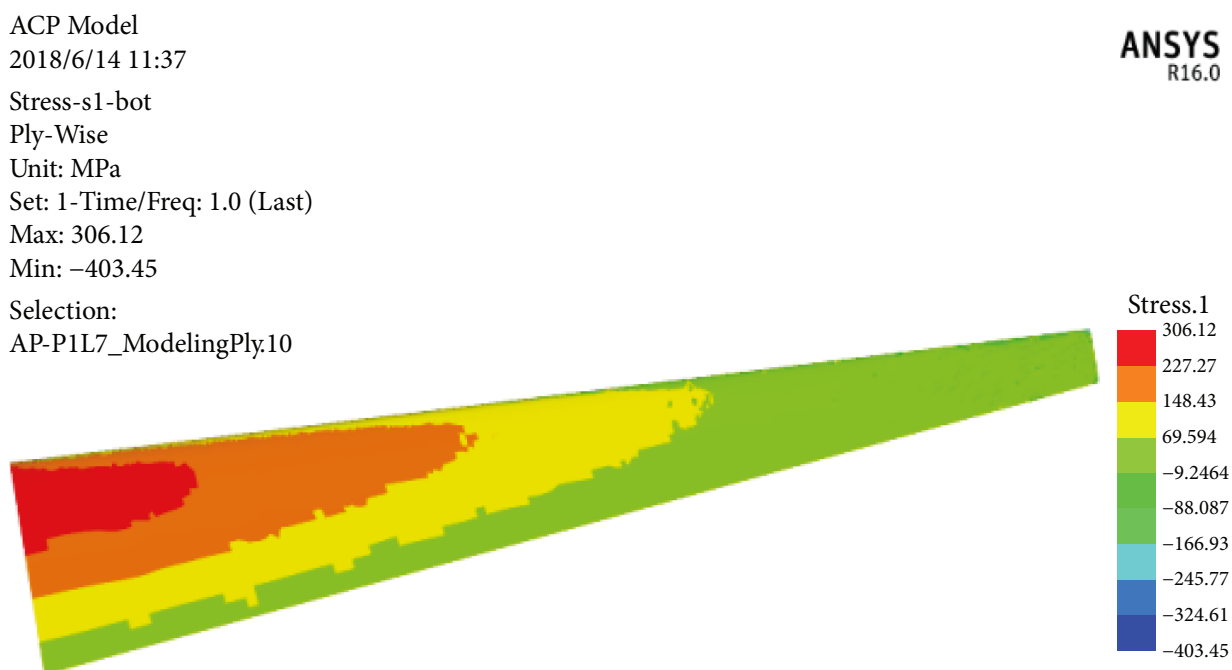

FIGURE 63: Stress cloud diagram of the lower wing with full composite.

TABLE 9: Structural performance of different materials.

\begin{tabular}{lccc}
\hline & Maximum stress $(\mathrm{MPa})$ & Maximum deformation $(\mathrm{mm})$ & $\mathrm{Mass}(\mathrm{kg})$ \\
\hline Full-composite wing & 309.34 & 315 & 220.09 \\
Full-metal wing & 263.88 & 570.97 & 382.41 \\
Variation & $17.2 \%$ & $44.83 \%$ & $42.45 \%$ \\
\hline
\end{tabular}

static analysis is carried out in the ACP module of ANSYS Workbench by using the aerodynamic load obtained. Next, the performance of the wing structure is analyzed and compared by changing different layering methods, and the performance of the structure under different materials is analyzed and compared as well. The whole design flow is summarized and the conclusions are summarized as follows:

(1) The structural properties of different thicknesses of the skin are compared, and the stiffness, strength, and weight reduction effects are considered comprehensively. Finally, $12 \mathrm{~mm}$ is chosen as a proper thickness of the skin

(2) Different laying methods have different impact on the performance of the skin, and the laying sequence, the laying angle, and the laying ratio are selected as variables in this paper, and it is concluded that the best laying methods of skin structure are the following three cases: 
(i) The \pm 45 ply is located at the outermost part of the ply

(ii) The strength of the layer with three standard angles mixed is higher than that with a single layer

(iii) When the ratio of three angles is $60 \% / 30 \% / 10 \%$, the performance of the structure is the best

(3) The mechanical properties of the composite structure are obviously superior to those of the metallic structure. Under the same load, the composite structure can reduce the maximum deformation and the structural mass effectively

\section{Data Availability}

The data used to support the findings of this study are included within the article.

\section{Conflicts of Interest}

The authors declare there is no conflict of interest regarding the publication of this paper.

\section{Acknowledgments}

The authors would like to express their thanks for the support from the National Natural Science Foundation of China (No. 11802340).

\section{References}

[1] D. Sziroczak and H. Smith, "A review of design issues specific to hypersonic flight vehicles," Progress in Aerospace Sciences, vol. 84, pp. 1-28, 2016.

[2] C. E. S. Cesnik, D. H. Hodges, and M. J. Patil, "Nonlinear aeroelastic analysis of aircraft with high-aspect-ratio wings," in 39th AIAA/ASME/ASCE/AHS/ASC Structures, Structural Dynamics, and Materials Conference and Exhibit, Long Beach, CA, USA, April 1998.

[3] Z. Shen and X. J. Zhang, Introduction of Structural Strength Design and Verification of Composite Aircraft, Shanghai Jiao tong University Press, Shanghai, 2011.

[4] L. Shi, Y. C. Deng, H. T. Gao, and W. Li, "Research on modeling criterion and methods for flexible wing structures with large aspect ratio," Aircraft Design, vol. 36, no. 6, pp. 1-4, 2016.

[5] W. S. Lu, S. P. Wang, and Y. C. Ma, "Static aeroelastic optimization design of composite wing with large aspect ratio based on CFD/CSD and Kriging interpolation model," Journal of Applied Mechanics, vol. 32, no. 4, pp. 581-585, 2015.

[6] M. M. Shokrieh and F. T. Behrooz, "Wing instability of a full composite aircraft," Composite Structures, vol. 54, no. 2-3, pp. 335-340, 2001.

[7] S. Takeda, Y. Aoki, T. Ishikawa, N. Takeda, and H. Kikukawa, "Structural health monitoring of composite wing structure during durability test," Composite Structures, vol. 79, no. 1, pp. 133-139, 2007.
[8] I. C. Taig, "Principles of design of a carbon fibre composite aircraft wing," Philosophical Transactions of the Royal Society A: Mathematical, Physical and Engineering Sciences, vol. 294, no. 1411 , pp. 565-575, 1980.

[9] T. Kim, J. Lim, S. J. Shin, and D. H. Kim, "Structural design optimization of a tiltrotor aircraft composite wing to enhance whirl flutter stability," Composite Structures, vol. 95, pp. 283294, 2013.

[10] M. J. Patil, D. H. Hodges, and C. E. S. Cesnik, "Nonlinear aeroelastic analysis of complete aircraft in subsonic flow," Journal of Aircraft, vol. 37, no. 5, pp. 753-760, 2000.

[11] J. Njuguna, "Flutter prediction, suppression and control in aircraft composite wings as a design prerequisite: a survey," Structural Control and Health Monitoring, vol. 14, no. 5, pp. 715-758, 2007.

[12] O. Seresta, Z. Gürdal, D. B. Adams, and L. T. Watson, "Optimal design of composite wing structures with blended laminates," Composites Part B: Engineering, vol. 38, no. 4, pp. 469-480, 2007.

[13] Y. Feng, X. T. Zheng, S. Y. Wu, and Z. D. Liu, "Optimization design of layer and analysis of lightweight composite wing cladding," Journal of Aviation, vol. 36, no. 6, pp. 1858-1866, 2015.

[14] Z. D. Liu, X. T. Zheng, Y. Feng, and D. Zhang, "Design and test verification of full composite wing structure for UAV," Journal of Composite Materials, vol. 33, no. 5, pp. 1055-1063, 2016.

[15] B. B. Ji and J. P. Chen, ANSYS ICEM CFD Grid Generation Technology, China Water Power Press, Beijing, 2012.

[16] N. B. Yang and W. Liang, Introduction to Airworthiness Conformity Proof of Aircraft Composite Structures, Aviation Industry Press, Beijing, 2015.

[17] T. T. Zhang, W. Huang, Z. G. Wang, and L. Yan, “A study of airfoil parameterization, modeling, and optimization based on the computational fluid dynamics method," Journal of Zhejiang University-Science A, vol. 17, no. 8, pp. 632-645, 2016.

[18] A. Y. Zhao, The layout of ribs in the wing box for Modern Civil Aircraft, Science \&Technology Vision, 2012.

[19] Y. S. Meng, L. Yan, W. Huang, T. T. Zhang, and Z. B. Du, "Structural design and analysis of a composite wing with high aspect ratio," in 8th European Conference for Aeronautics and Space Sciences (EUCASS), Madrid, Spain, 2019.

[20] W. P. Yang, Composite Structural Stress Analysis of Aircraft, Aviation Industry Press, Beijing, 2018. 


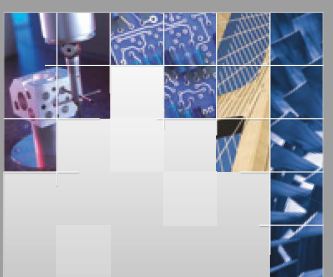

\section{Enfincering}
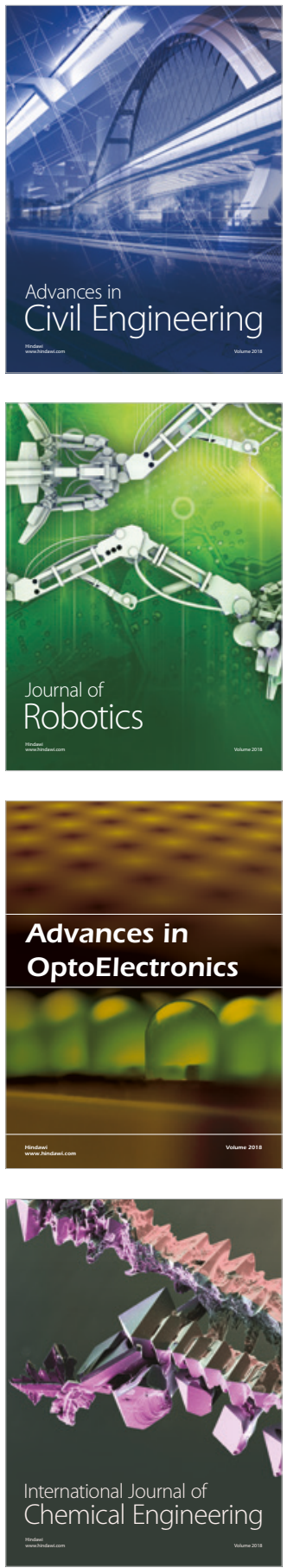

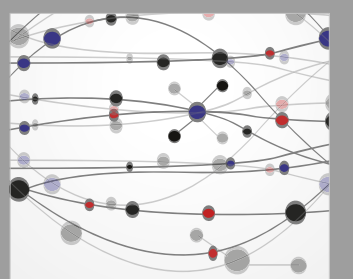

\section{Rotating \\ Machinery}

The Scientific World Journal

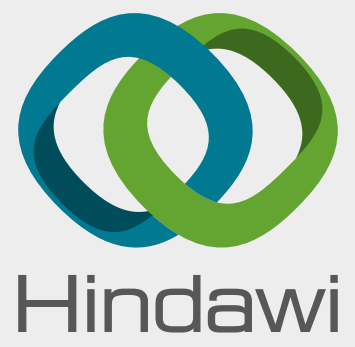

Submit your manuscripts at

www.hindawi.com
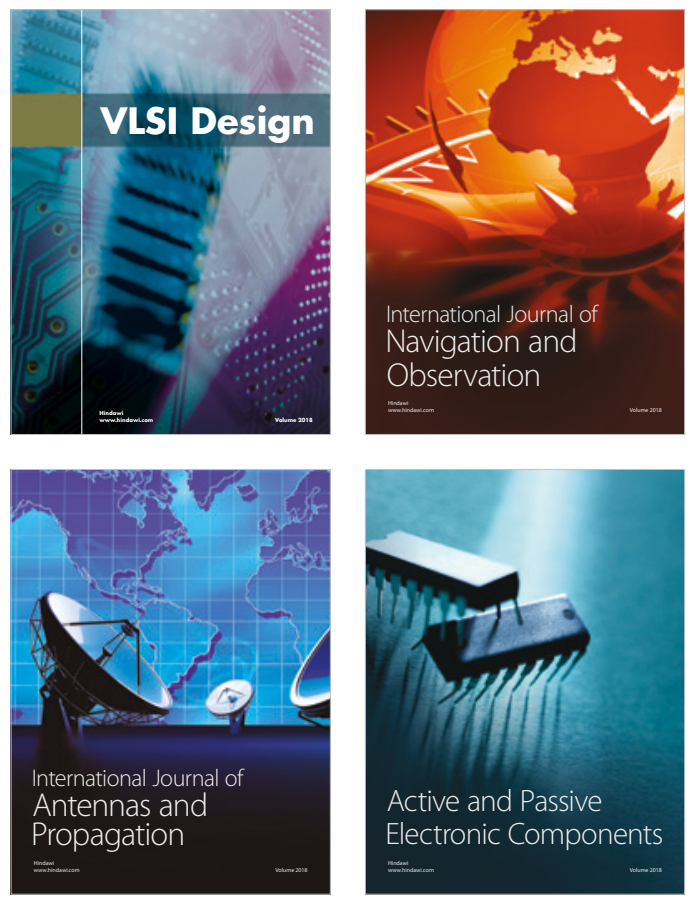
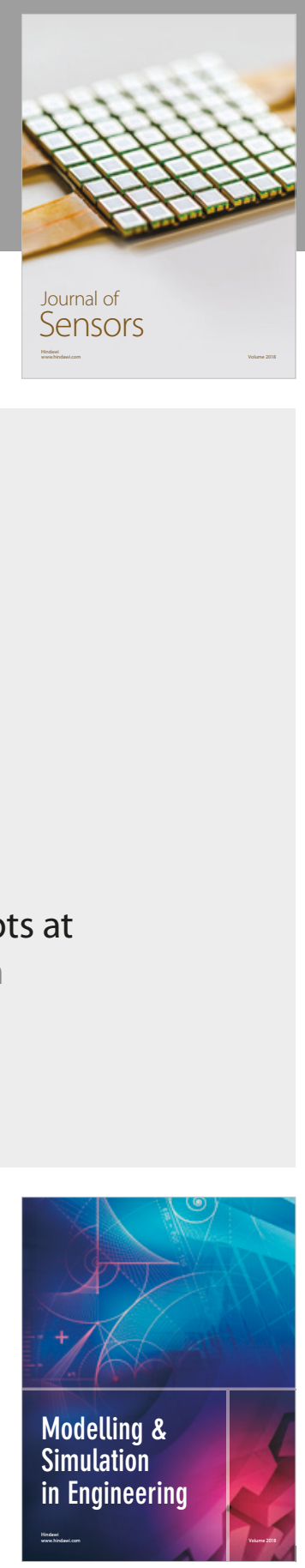

\section{Advances \\ Multimedia}
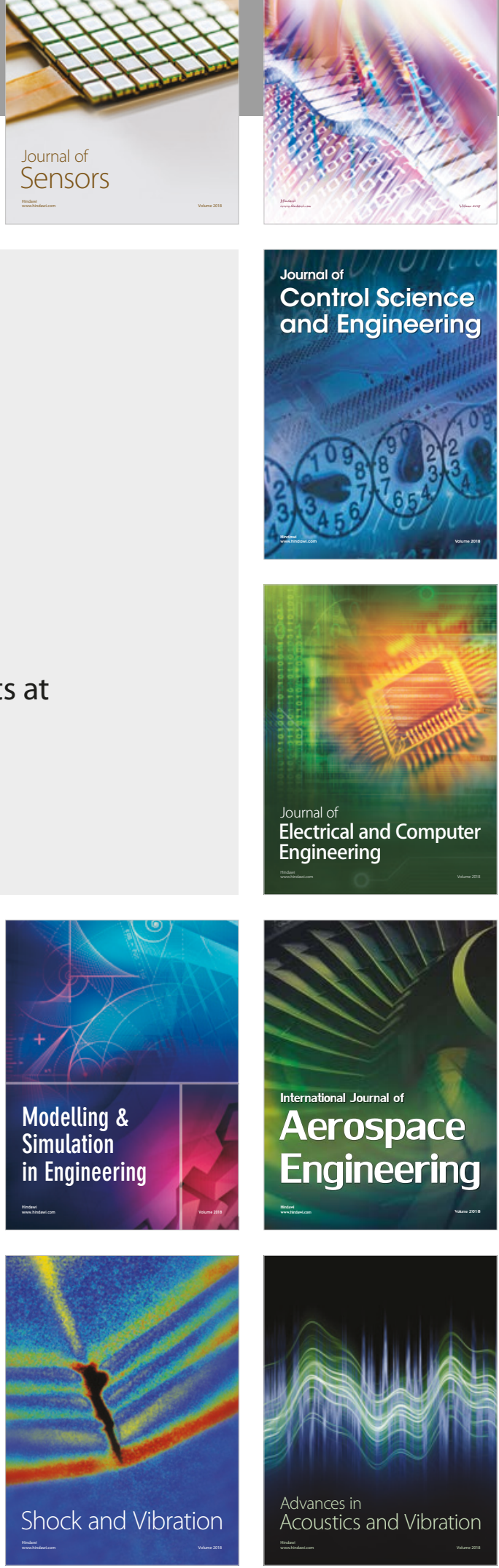